\title{
Assessing and Combining Financial Conditions Indexes*
}

\author{
Sirio Aramonte, ${ }^{\mathrm{a}}$ Samuel Rosen, ${ }^{\mathrm{b}}$ and John W. Schindler ${ }^{\mathrm{a}}$ \\ ${ }^{\text {a}}$ Federal Reserve Board \\ ${ }^{\mathrm{b}}$ University of North Carolina at Chapel Hill, Kenan-Flagler \\ Business School
}

We evaluate the short-horizon predictive ability of financial conditions indexes for stock returns and macroeconomic variables. We find reliable predictability only when the sample includes the 2008 financial crisis, and we argue that this result is driven by tailoring the indexes to the crisis and by nonsynchronous trading. In addition, we suggest a simple procedure for aggregating the various indexes into a single proxy for financial conditions, which can help to reduce the uncertainty faced by policymakers when monitoring financial conditions.

JEL Codes: E32, G01, G17.

\section{Introduction}

The severity and the economic impact of the 2008 financial crisis have led to a proliferation of indexes that proxy for financial conditions or financial stress, which we collectively refer to as financial conditions indexes (FCIs). An open question in the literature is

${ }^{*}$ We would like to thank Kathryn Smith for research assistance, and participants of several Federal Reserve Quantitative Surveillance Group meetings. We would also like to thank Malcolm Spittler and Troy Matheson for providing data and guidance for, respectively, the Citi Financial Conditions Index and the International Monetary Fund U.S. Financial Conditions Index, and Mark Carlson, Kurt Lewis, and William Nelson, and Roberto Cardarelli, Selim Elekdag, and Subir Lall for providing data and guidance for, respectively, their Financial Market Stress Index and the International Monetary Fund U.S Financial Stress Index. This article represents the views of the authors and should not be interpreted as reflecting the views of the Board of Governors of the Federal Reserve System or other members of its staff. Corresponding author: sirio.aramonte@frb.gov; Tel.: $+1-202-912-4301$. 
whether these indexes should be used as indicators of current financial conditions, or whether they also have predictive power for future financial and economic activity and could be used as early-warning indicators. In this paper we evaluate whether FCIs can predict stock returns or innovations to macroeconomic variables over a one-month or a one-quarter horizon. In addition, we study the Granger causality relation between the FCIs and several measures of credit availability that we use as proxies for the "financial cycle" (Borio 2014). Finally, we suggest a simple procedure for aggregating the various FCIs into a single proxy for financial conditions.

We find that most FCIs can predict monthly and quarterly returns on the S\&P 500 and on a portfolio of financial companies and also innovations to a number of macroeconomic variables. However, this predictability is not robust to excluding the period around the 2008 financial crisis (2007-12). We posit three possible explanations for this pattern. The first is threshold effects, in the sense that financial conditions may matter only after deteriorating beyond a certain threshold. The second is data mining, because most of the FCIs were introduced after the financial crisis, and they are built using variables that displayed significant movements during the crisis. And the third is non-synchronous data, given that most FCIs include one variable derived from the prices of options that trade after equity markets close, hence FCIs include, by construction, information that will be incorporated in stock prices the next day. We provide evidence that all three effects are present, but we argue that predictability is mainly driven by data mining and by non-synchronous trading.

The FCIs we study measure financial conditions in one of two ways. The first approach is to evaluate whether broad financial conditions are loose or tight by historical standards (e.g., the Bloomberg and Chicago Fed indexes). Alternatively, other indexes purport to measure whether the financial system is experiencing historically unusual stress (e.g., the Carlson, Lewis, and Nelson 2014 index). Despite these and other methodological differences that we detail in section 2, the FCIs exhibit a large amount of common variation, as can be seen in the top graph in figure 1. Such a result is expected because, while the concept of "financial conditions" is often only loosely defined by the articles that build the various FCIs, changes in the state of the financial system directly affect many of the variables used to build the FCIs. However, the top graph in figure 1 


\section{Figure 1. Time-Series Plots of the Twelve Financial Conditions Indexes}

All Indexes Except for IMF FSI and CLN FSI
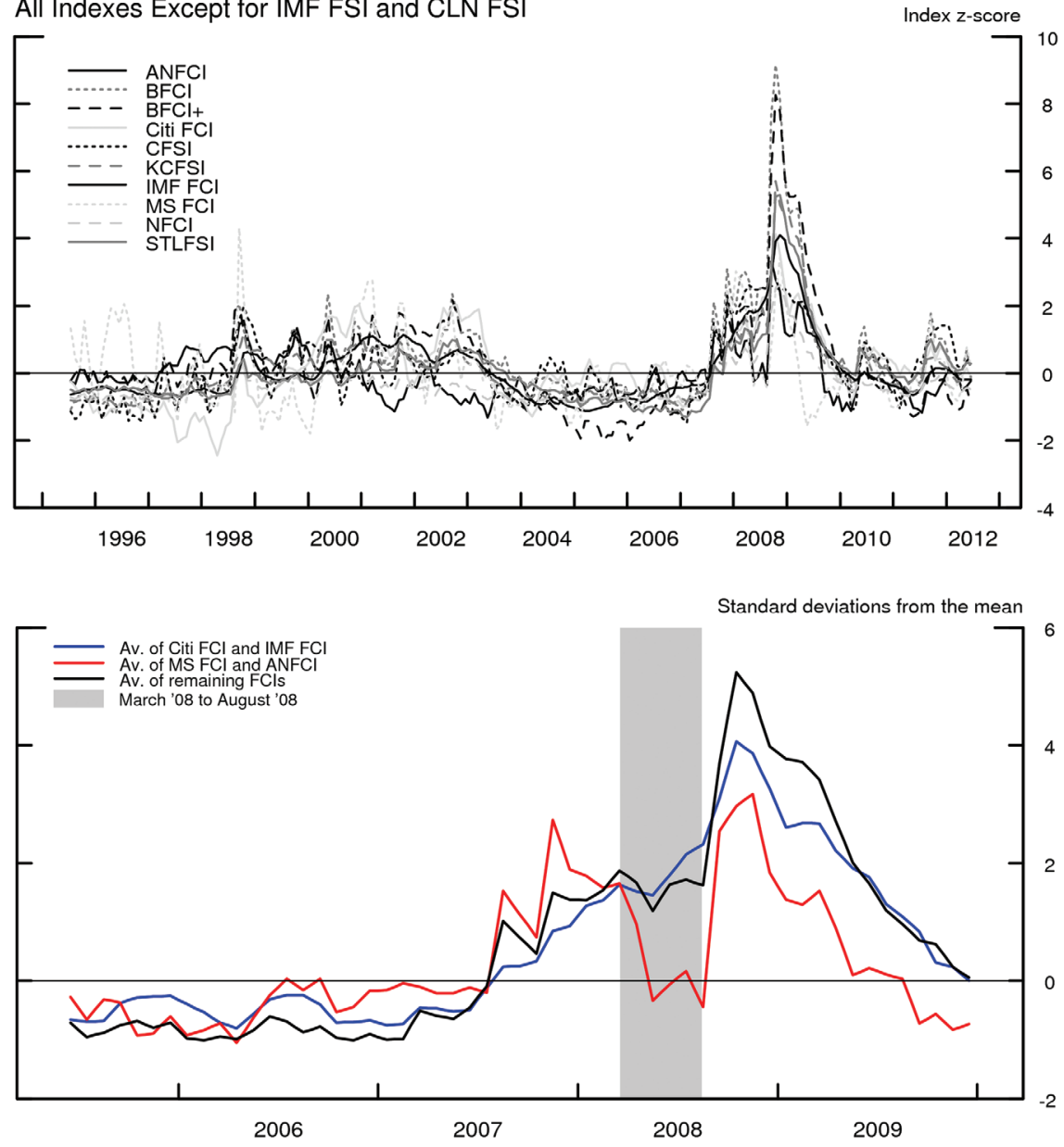

Notes: The graphs show the time series of the twelve FCIs we study. For scale reasons, the International Monetary Fund (IMF) U.S. Financial Stress Index and the Carlson, Lewis, and Nelson (2014) Financial Stress Index are not shown. The bottom graph focuses on the years surrounding the 2008 financial crisis, and it shows the averages of standardized versions of (i) Citi FCI and IMF FCI, (ii) MS FCI and ANFCI, and (iii) the remaining FCIs. See table 1 for a list of FCI acronyms. 
shows that, at certain points in time, different indexes provide a conflicting reading of financial conditions. This was the case, for instance, in 1997-98 for the Citi FCI and 2004-05 for one of the Bloomberg FCIs. In section 3, we propose a method to extract a single and more precise measure of financial conditions from the set of indexes we consider.

Having a reliable measure of financial conditions is important for policymakers because, as the literature has shown, financial conditions matter in a variety of ways. The importance of a wellfunctioning financial system to the broad economy is highlighted by the results in Bernanke and Blinder (1992), Kashyap, Stein, and Wilcox (1993), Kashyap, Lamont, and Stein (1994), Peek and Rosengren (1997), and Paravisini (2008), who show that tight monetary policy, binding capital ratios, and bank financing constraints can reduce the supply of credit, especially in the case of small banks with less liquid assets (Kashyap and Stein 2000). A reduced credit supply has particularly negative effects for small firms (Gertler and Gilchrist 1994, Khwaja and Mian 2008) and bank-dependent borrowers (Chava and Purnanandam 2011). A tight credit supply ultimately affects investment (Campello, Graham, and Harvey 2010), inventories (Kashyap, Lamont, and Stein 1994), and the broader economy (Bernanke 1983; Peek and Rosengren 1997, 2000; Calomiris and Mason 2003).

We assess predictability using simple predictive regressions of a set of stock returns or innovations to macroeconomic variables on lagged FCI values. Our analysis differs from Hatzius et al. (2010), who also evaluate the predictive power of several FCIs, in a few important ways. First, we only consider FCIs that are updated at least monthly (we should emphasize that, as shown in figure 1, the FCIs still have meaningful monthly variation), and we study their predictive power for stock returns and innovations to macroeconomic variables one month and one quarter ahead. By using such horizons, our predictability results are unlikely to reflect business-cycle effects, especially in the case of one-month-ahead regressions. Second, we study a larger number of FCIs and a larger number of financial and macroeconomic variables. Third, we explicitly discuss whether the predictability that arises in coincidence with the 2008 financial crisis is hard-wired in the FCIs, in the sense that the variables included in the FCIs may have been chosen on the basis of whether they 
experienced large fluctuations in 2007 and 20081 Finally, as described in more detail in section 2 , we assess the statistical significance of predictability with a methodology that is robust to biases generated by the high persistence that typically characterizes FCIs, which we found had noticeable effects on the results discussed in section 2 .

Our conclusions differ from those of English, Tsatsaronis, and Zoli (2005), who focus on four- and eight-quarter horizons, and consider a longer sample than we do. They aggregate financial variables with principal component analysis and find that the resulting proxies for financial conditions have some predictive power for macroeconomic variables. Our conclusions, however, are more in line with those of Hatzius et al. (2010), because we find limited value in using FCIs as reliable early-warning indicators, especially when (i) excluding the period surrounding the 2008 financial crisis from the sample, and (ii) acknowledging that the choice of the variables that enter many FCIs may have been influenced by knowing, in hindsight, what precipitated the financial crisis.

In the second part of our paper, we discuss a simple two-step methodology for combining the various FCIs into a single proxy for financial conditions. The large number of FCIs is itself indicative of the uncertainty that surrounds the measurement of financial conditions. In the top graph in figure 1, one can see that the FCIs generally move together in the long run, but they can provide conflicting assessments at a given point in time - even shortly before a major financial crisis. For instance, the bottom graph in figure 1 shows the averages of three sets of (standardized) FCIs between 2006 and 2009. The shaded area highlights the period between March and August 2008, which corresponds to the months between the purchase of The Bear Stearns Companies, Inc. by JPMorgan Chase \& Co. (March 16, 2008) and the bankruptcy filing of Lehman Brothers Holdings Inc. on September 15, 2008. The chart clearly shows that

\footnotetext{
${ }^{1}$ For example, Hatzius et al. (2010) develop their own FCI in addition to evaluating others. They note on page 21 that "the better performance during the most recent five years ... may reflect selection bias in our choice of variables to include in the index: naturally, our selection was governed in part by an understanding of the types of financial variables that were used for monitoring and measuring the recent financial crisis. In this sense, we did not seek to mitigate observer bias."
} 
different FCIs give conflicting readings of the state of the financial system in the second and third quarters of 2008, ranging from a noticeable deterioration to a large improvement.

Aggregating the individual indexes can help average out model uncertainty and provide policymakers with a single variable that reflects the information available in all of the FCIs. We first identify the indexes that best summarize the information provided by the remaining FCIs. In the second step we form all combinations of the identified indexes and select the "best" combination on the basis of how well it summarizes the information in the remaining FCIs. This procedure is discussed in detail in section 3 .

\section{Assessing the Predictive Ability of FCIs}

We consider twelve FCIs that (i) focus on the United States, (ii) are updated at least every month, and (iii) have a sufficiently long history 2 Table 1 contains a detailed list of data sources and includes the abbreviated FCI names we use in the paper.

The construction of the FCIs varies considerably, although all of them are largely based on financial market variables, including implied volatilities, Treasury yields, yield spreads, commercial paper rates, stock returns, and exchange rates (see Kliesen, Owyang, and Vermann 2012 for a detailed list of variables that underlie a range of the FCIs we study here). Some FCIs only include a small set of variables, as in the case of the Bloomberg Financial Conditions Index, which is based on ten underlying variables. One index, the Chicago Fed Adjusted National Financial Conditions Index, has more than 100 underlying variables.

In general, the constituent variables are aggregated using principal component analysis or simple weighted sums. Principal component analysis is used extensively in the literature to extract information from a large set of macroeconomic or financial variables for forecasting purposes. For example, Ludvigson and Ng (2007) rely

\footnotetext{
${ }^{2}$ In order to increase the power of our test, we require that the FCIs cover the stressful episodes that characterized the late 1990s (the Long-Term Capital Management collapse, and the Asian and Russian financial crises). For this reason, we do not include the HSBC Financial Clog Index (Bloomberg ticker HSCLOG Index) or the Westpac U.S. Financial Stress Index (Bloomberg ticker WRAISTRS Index), whose series start in 2007 and 1998, respectively.
} 
Vol. 13 No. 1 Assessing and Combining Financial Conditions 7

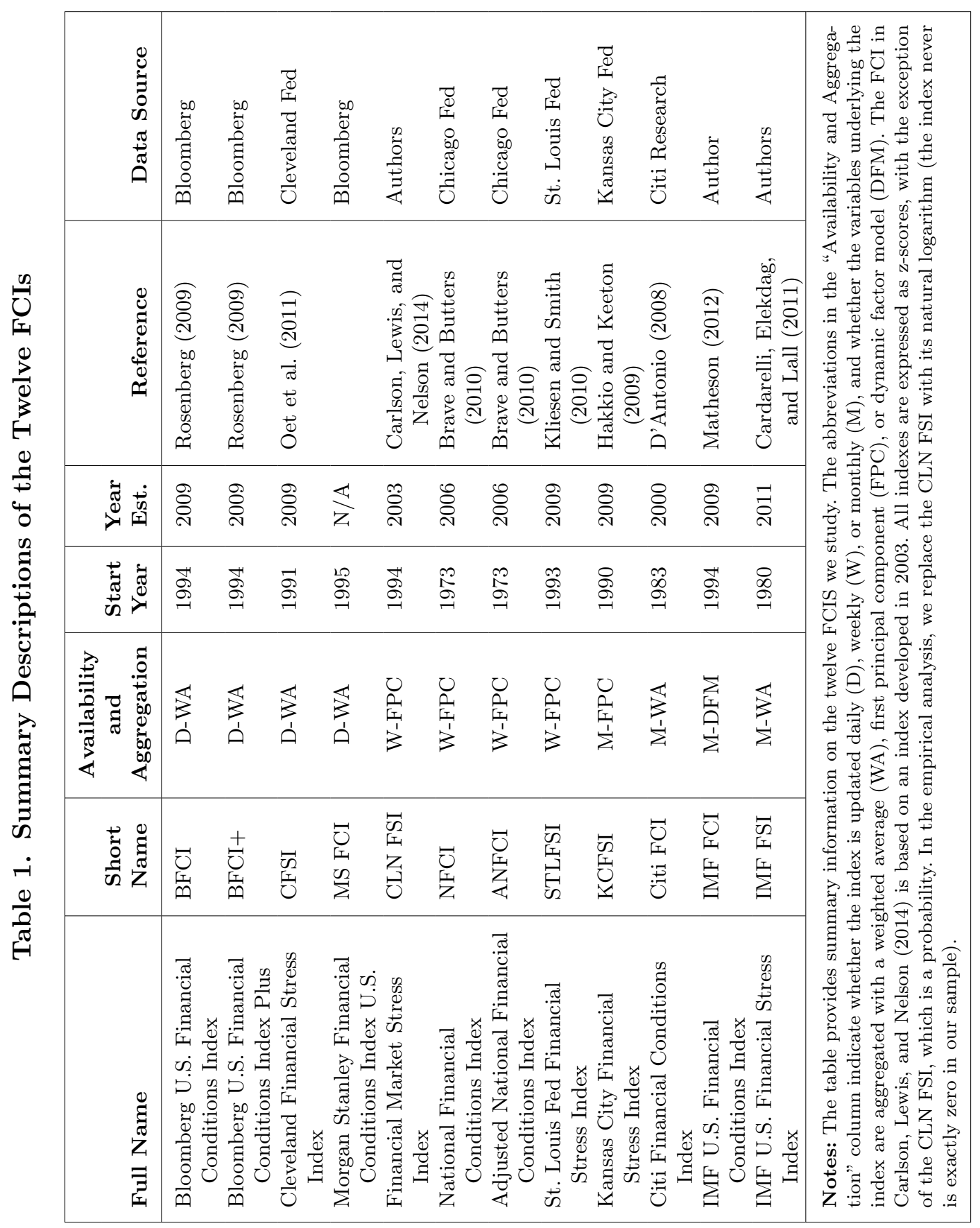


on dynamic factor analysis to summarize a broad cross-section of variables, and find that several of the resulting factors can predict one-quarter-ahead excess stock returns. Stock and Watson (2002) use principal component analysis to build factors used to predict several macroeconomic variables in the medium run (six, twelve, and twenty-four months ahead).

For indexes constructed as weighted sums, weights are typically assigned subjectively by the authors, although a few of the indexes use more sophisticated methods. The Cleveland Financial Stress Index (CFSI), for instance, calculates weights dynamically based on the relative dollar flow observed in the Federal Reserve Board's Flow of Funds statistical release (Z.1) (Oet et al. 2011). All the indexes are expressed in terms of z-scores, with the exception of the Financial Stress Index of Carlson, Lewis, and Nelson (2014), which is expressed in terms of probabilities.

\subsection{Predictive Regressions}

We evaluate the predictive power of the twelve FCIs with a series of monthly and quarterly predictive regressions of the form

$$
y_{t}=\alpha+\beta \times F C I_{t-1}+\epsilon_{t} .
$$

The FCIs enter the regression in levels, rather than changes, because the developers of most of the FCIs emphasize that their indexes are ordinal measures of financial conditions/stress.

We focus on one-month-ahead and one-quarter-ahead regressions because our predictability results might in part reflect business-cycle effects if the dependent variable were measured over longer horizons. In particular, many FCIs include the implied volatility index VIX as a constituent variable. Bollerslev, Tauchen, and Zhou (2009) find that the variance risk premium, which is the difference between the squared value of VIX and a measure of realized variance, can predict stock returns about three to six months out, with the associated adjusted $\mathrm{R}^{2}$ peaking at a five-month horizon and declining gradually at longer horizons. The variance risk premium is driven by the dynamics of both volatility risk and risk aversion; the latter is embedded in VIX, and its evolution over time has a business-cycle component. Note that we do not control for the predictive power of other variables, like the variance risk premium, because the results 
from regressions in which FCIs are the only predictor already suggest a lack of reliable predictive power at the horizons we focus on.

The FCI coefficient is estimated with OLS, and we assess its statistical significance with either heteroskedasticity-consistent standard errors or the local-to-unity asymptotics procedure of Campbell and Yogo (2006). Local-to-unity asymptotics are useful in evaluating the statistical significance of persistent predictors, because, in such cases, the standard $t$-test can give a rejection rate that is inconsistent with its nominal size.

As is clear from the time-series plots in figure 1, FCIs tend to be quite persistent. The high autocorrelation that characterizes the FCIs is also evident in the confidence intervals for the autoregressive roots shown in table 23 We report confidence intervals, rather than point estimates, to highlight that, after accounting for statistical uncertainty, the FCIs plausibly have autoregressive roots very close to one. In five cases, we are actually unable to reject the hypothesis that the FCIs have a unit root. Given the nature of the problem we study, asymptotic standard errors would normally be biased against finding predictability, and the local-to-unit asymptotics procedure of Campbell and Yogo (2006) corrects for this bias. Our results show that the Campbell and Yogo (2006) procedure finds predictability 25 percent more often than OLS for innovations to macroeconomic variables, and six times as often for stock returns 4

\footnotetext{
${ }^{3}$ The procedure for calculating the confidence intervals in table 2 is described in the online appendix to Campbell and Yogo (2006).

${ }^{4}$ The direction and severity of the bias depend on the persistence of the predictor, on the correlation between the innovations to the predictor and to the predicted variable $(\delta)$, and on the sign of the predictive relation (see the discussion on the skewness of the $t$-statistic distribution in section 3.2 of Campbell and Yogo 2006). Given the persistence of the FCIs, and assuming that poor financial conditions lead to negative returns/innovations to macroeconomic variables, OLS should find predictability less often than the Campbell and Yogo (2006) procedure for FCIs that increase in value when financial conditions deteriorate. In order to run the Campbell and Yogo (2006) procedure, we need to make sure that the correlation $\delta$ is negative, and we do so by multiplying an FCI by -1 if needed. The figures mentioned in the text refer to predictive regressions based on the full sample and where the FCIs, after being multiplied by -1 if needed, increase in value when financial conditions deteriorate. This is the case for all the full-sample regressions that predict returns, and for 78 percent of the full-sample regressions that predict innovations to macroeconomic variables.
} 


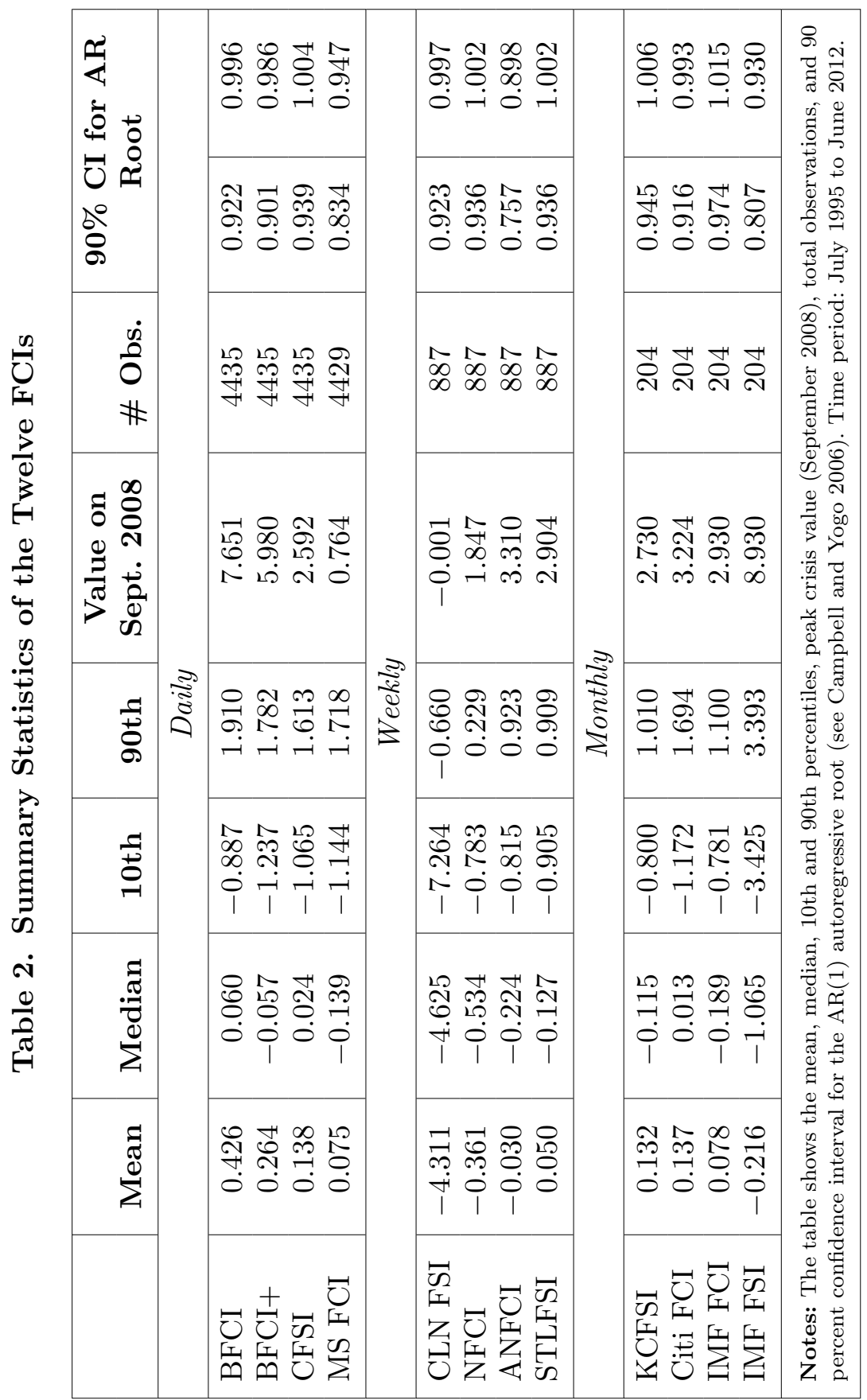


In practice, we assume that each of the FCIs follows an $\mathrm{AR}(1)$ process, and use local-to-unity asymptotics unless the autoregressive root of the FCI is sufficiently distant from one, in a sense defined in footnote 5 , or unless there is no correlation between the innovations to the FCI's autoregressive process and the innovations in a regression of the predicted variable on the FCI 5 Note that both a persistent predictor and a non-zero correlation are necessary for the standard OLS asymptotics to be inappropriate.

The dependent variables in our predictive regressions are (i) returns on a broad market index and on various industry portfolios, and (ii) autoregressive residuals of log-changes in several economic variables; we study residuals because, unlike returns, changes in macroeconomic variables can be autocorrelated. We consider monthly and quarterly returns on the S\&P 500 and on seven equally weighted industry portfolios: finance, construction, manufacturing, transportation, wholesale trade, retail trade, and services. The macroeconomic variables we consider measure the availability of credit (total consumer credit, and commercial and industrial loans), the state of the housing market (housing starts), and manufacturing activity (durable goods orders, industrial production, and total manufacturing inventory) 6

We present the results for the predictability of stock returns in tables 4 through 7 . For each portfolio/FCI combination we report the coefficient on the FCI $\left(\beta_{F C I}\right)$ and the regression root mean squared error (RMSE). We show an asterisk next to a coefficient when the coefficient is statistically significant at the 90 percent confidence level.

${ }^{5}$ Using the notation in Campbell and Yogo (2006), we rely on heteroskedasticity-consistent standard errors if the DF-GLS statistic is less than -5 (a more negative DF-GLS statistic shifts the confidence interval for the autoregressive root of the predictor away from one), or if the parameter $\hat{\delta}$ (which measures the correlation between the innovations) is equal to zero. When needed, we linearly interpolate the values obtained from the lookup tables in the online appendix to Campbell and Yogo (2006), which only provide a discrete set of values for $\hat{\delta}$ and of the DF-GLS statistic.

${ }^{6}$ Stock returns are from the Center for Research in Security Prices (CRSP) through Wharton Research Data Services. The macroeconomic data are from the Federal Reserve Economic Data (FRED) database of the Federal Reserve Bank of St. Louis. See table 3 for summary statistics and additional details on the construction of the industry portfolios. 


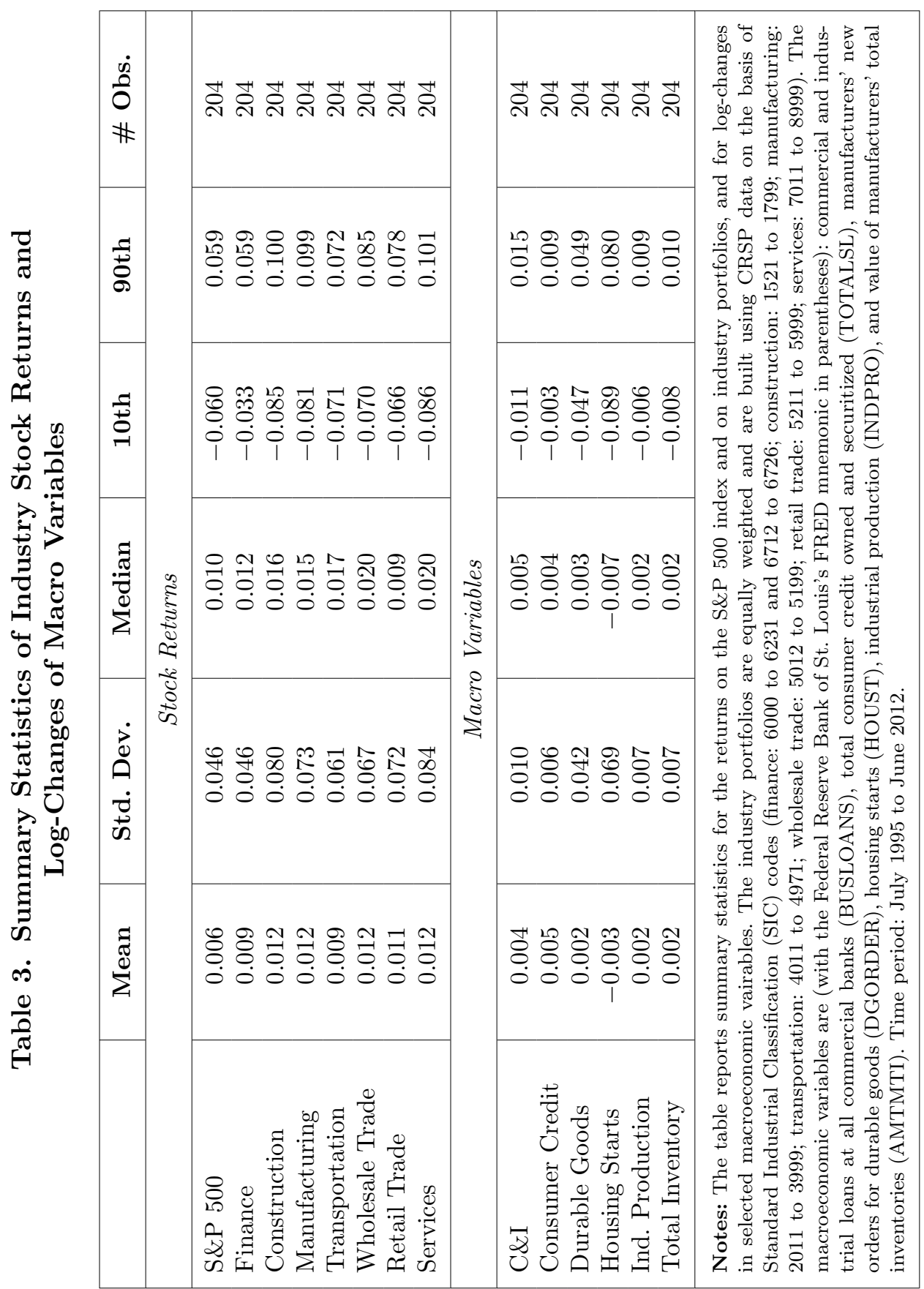


Table 4 shows results for the 1995-2012 sample, and it indicates that eleven of the twelve FCIs can predict returns on the finance industry portfolio, that four can predict the S\&P 500, and that the Morgan Stanley index can predict returns on the finance and three additional industry portfolios. There is noticeable dispersion in the RMSEs across industry portfolios for a given FCI, with the construction and services portfolios generally showing the largest RMSE and the finance portfolios the lowest, but the RMSEs are remarkably similar across FCIs for a given portfolio. The statistically significant coefficients have the expected negative sign, indicating that higher levels of financial stress (or tighter financial conditions) tend to be followed by lower returns.

The severity of the 2008 financial crisis naturally raises the question of whether the predictive power of the FCIs mainly arises from the events that started in early 2007, or whether it is also present in the broader sample. In table 5 we report the coefficients and RMSEs estimated over the 1995-2006 sample, and the results highlight that, essentially, there is no meaningful predictability left. Later in this section we discuss whether the lack of predictive power outside of the 2008 crisis is due to predictability only being there during periods of financial stress, or whether it is the result of the FCIs being tailored to the recent financial crisis.

The conclusions that we can draw from monthly returns also carry over to quarterly returns (tables 6 and 7 ). Five FCIs have predictive power for returns on the $\mathrm{S} \& \mathrm{P} 500$ or on the financial industry portfolio in the 1995-2012 sample. Similar to the monthly analysis, returns on the remaining industry portfolios are not predictable.

Restricting the sample to the pre-crisis period (1995-2006, table 7) all but eliminates the predictability, with the exception of the Morgan Stanley index, which can now predict returns on five portfolios. Note that the coefficients for the Morgan Stanley index are positive, while they were negative at the monthly horizon in the full sample (table 4). This difference is consistent with the possibility that measuring returns over longer horizons captures the early signs of a turning business cycle. The Morgan Stanley index may signal poor financial conditions when the business cycle is close to its trough, and, while one-month-ahead returns may still be negative as the economy bottoms out, one-quarter-ahead returns may already capture the initial pickup in economic activity. 


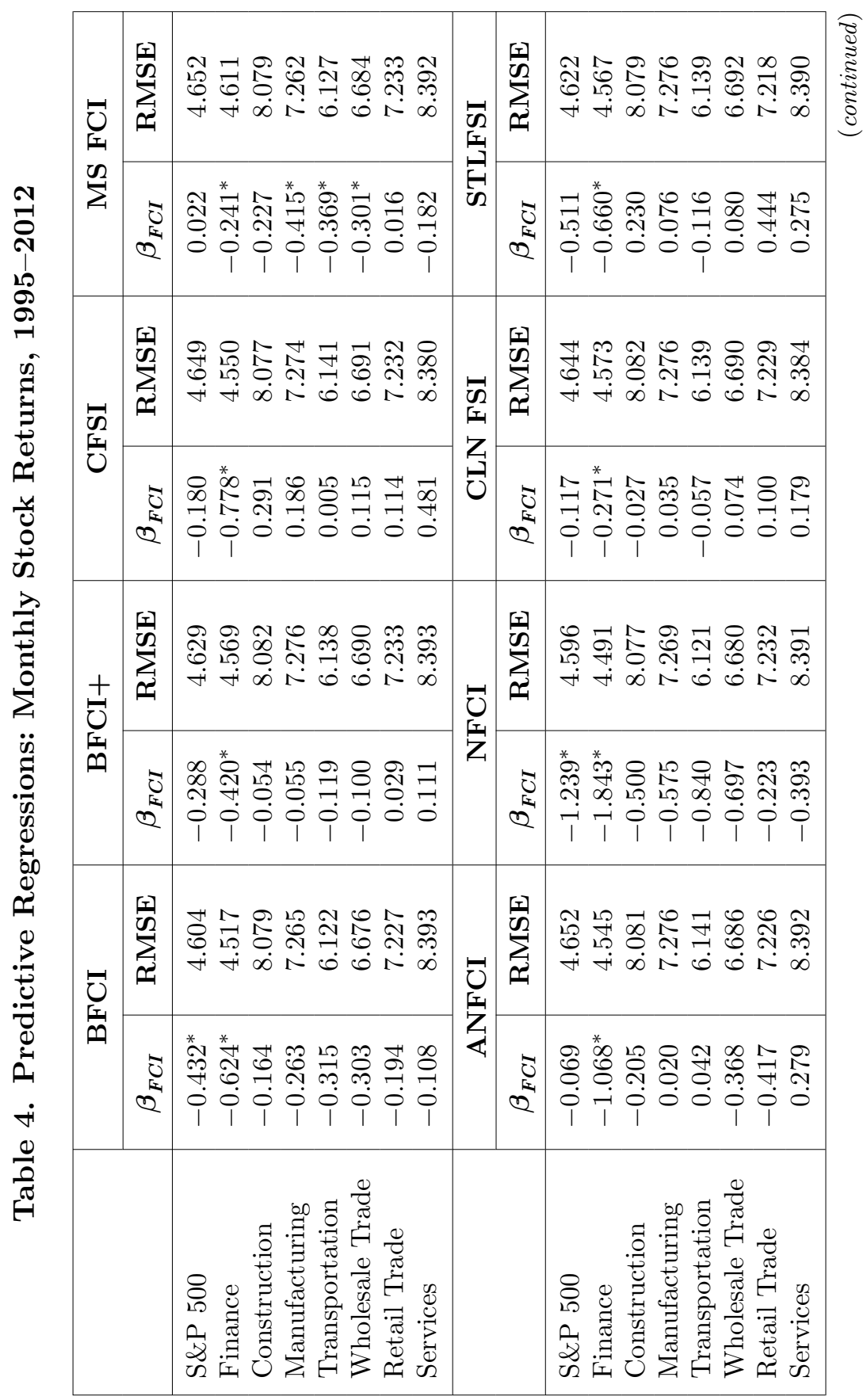




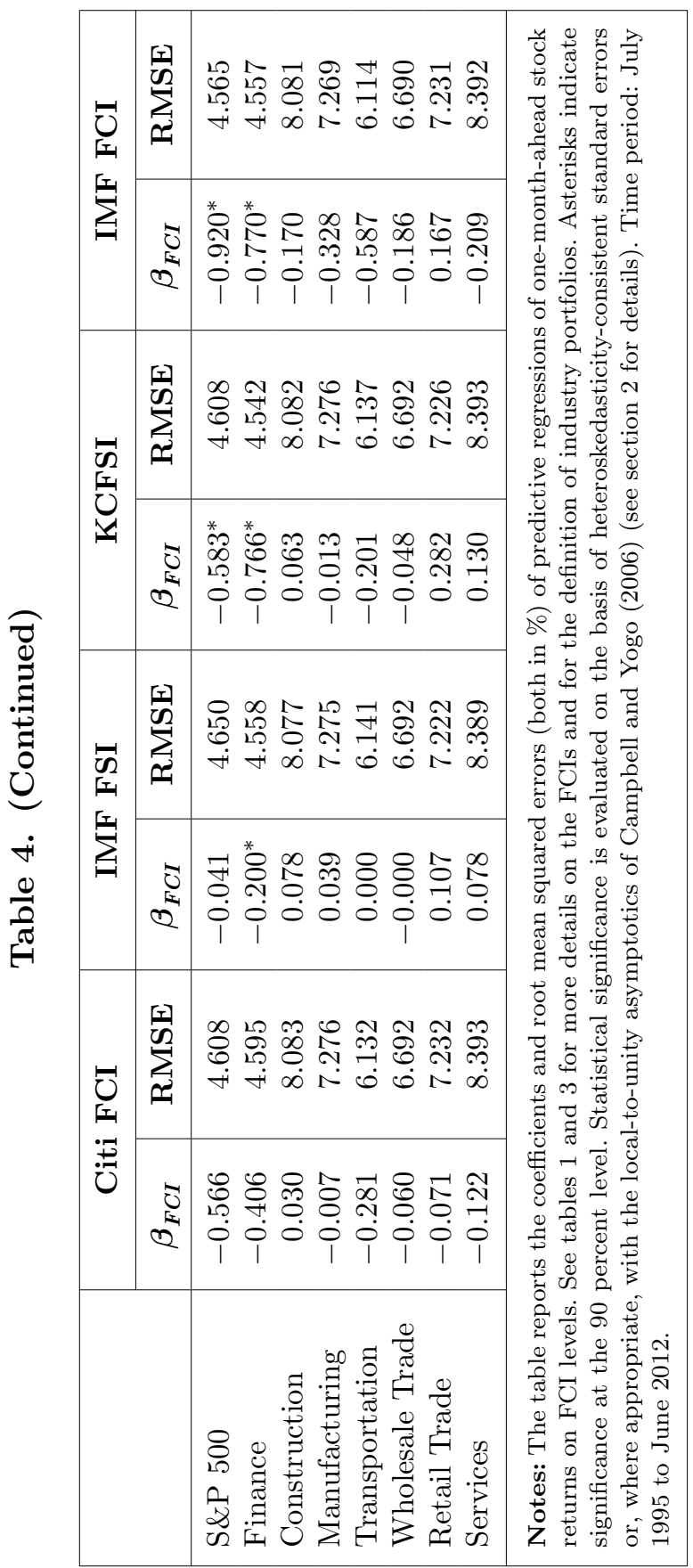




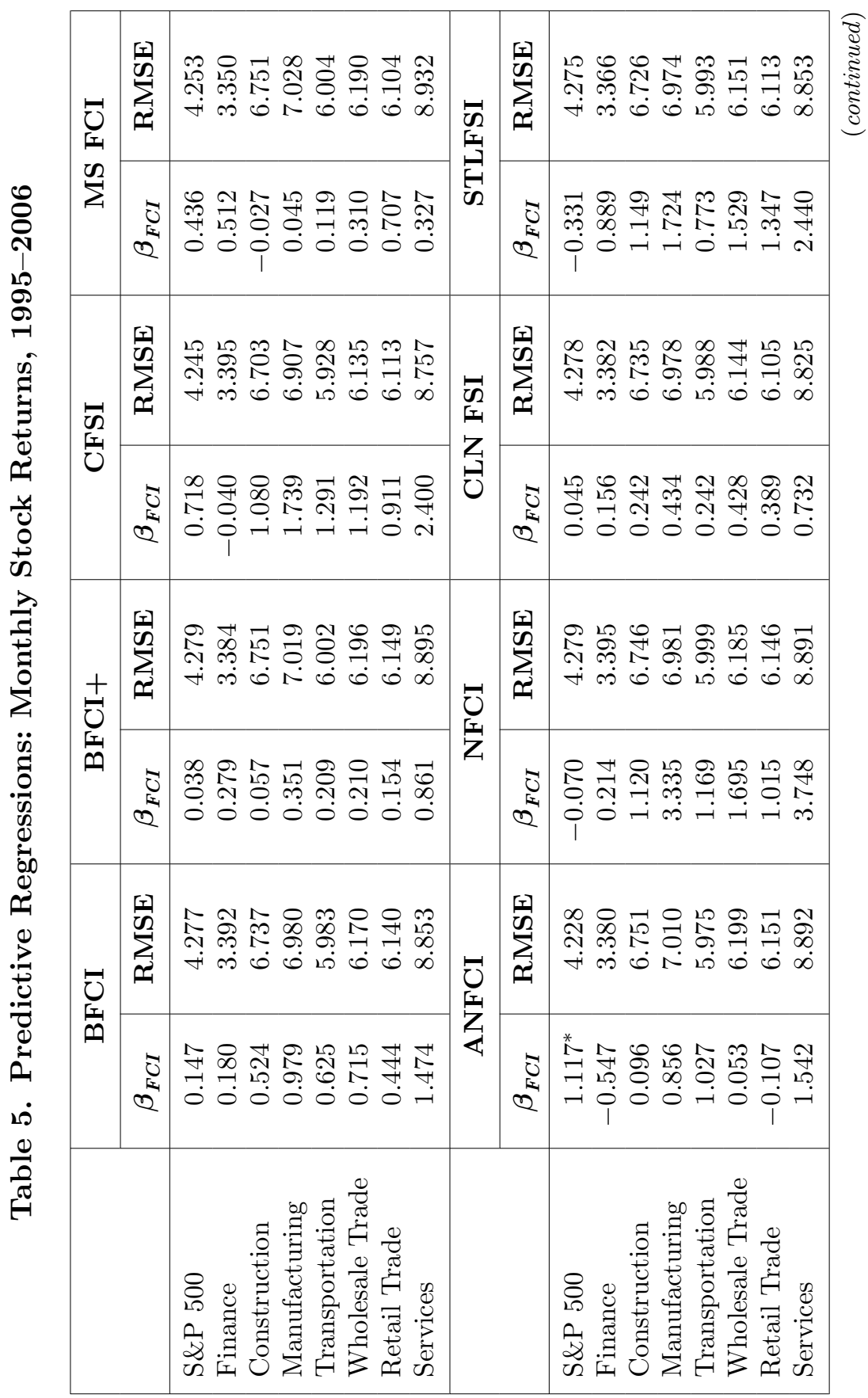




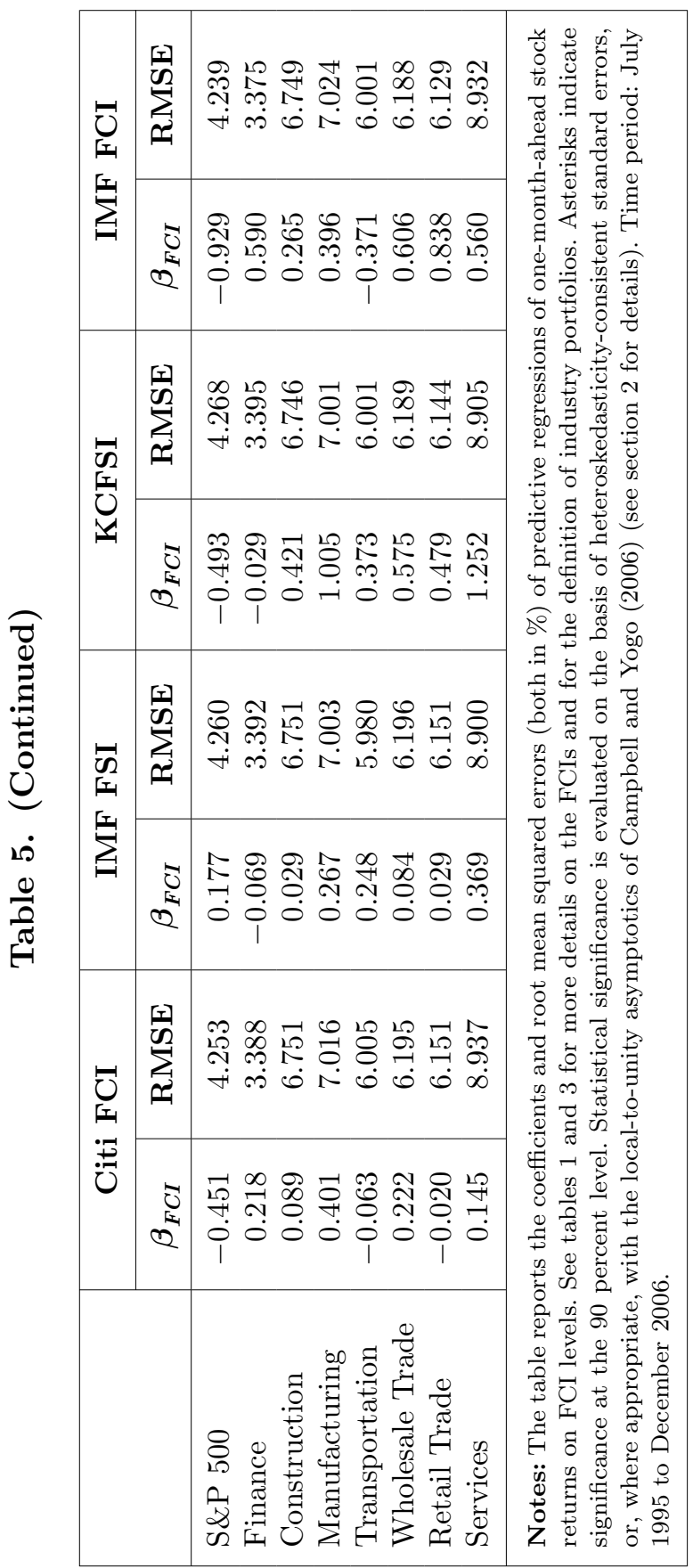




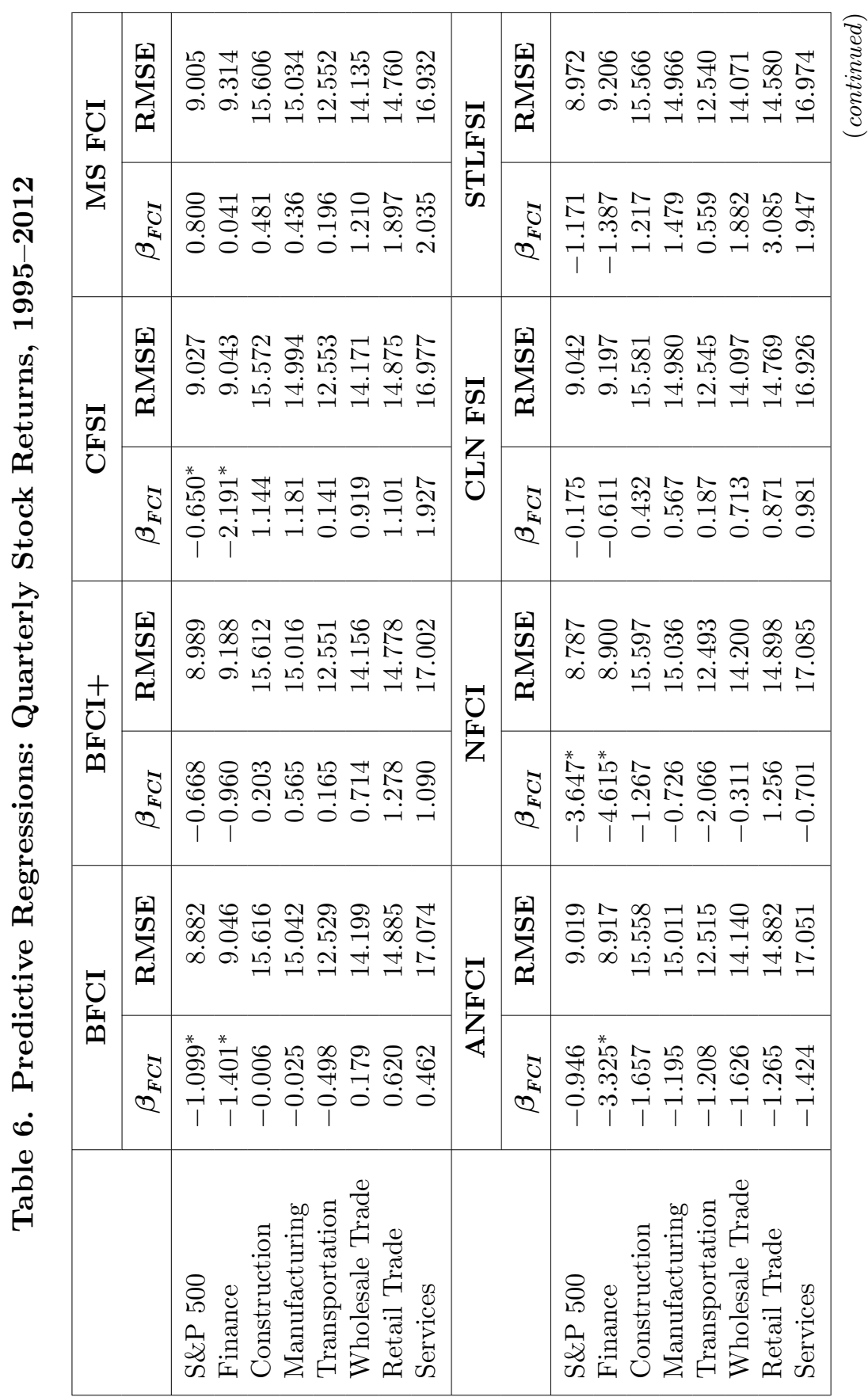




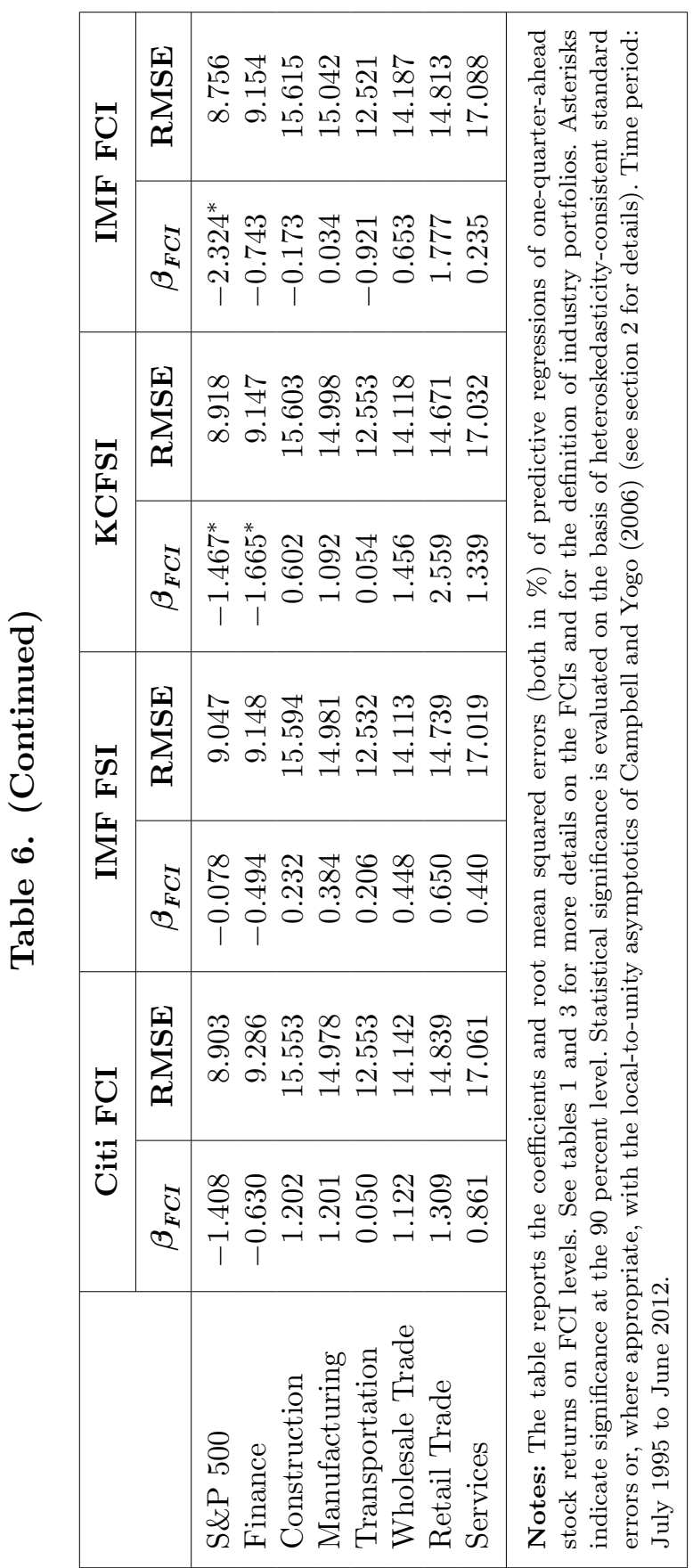




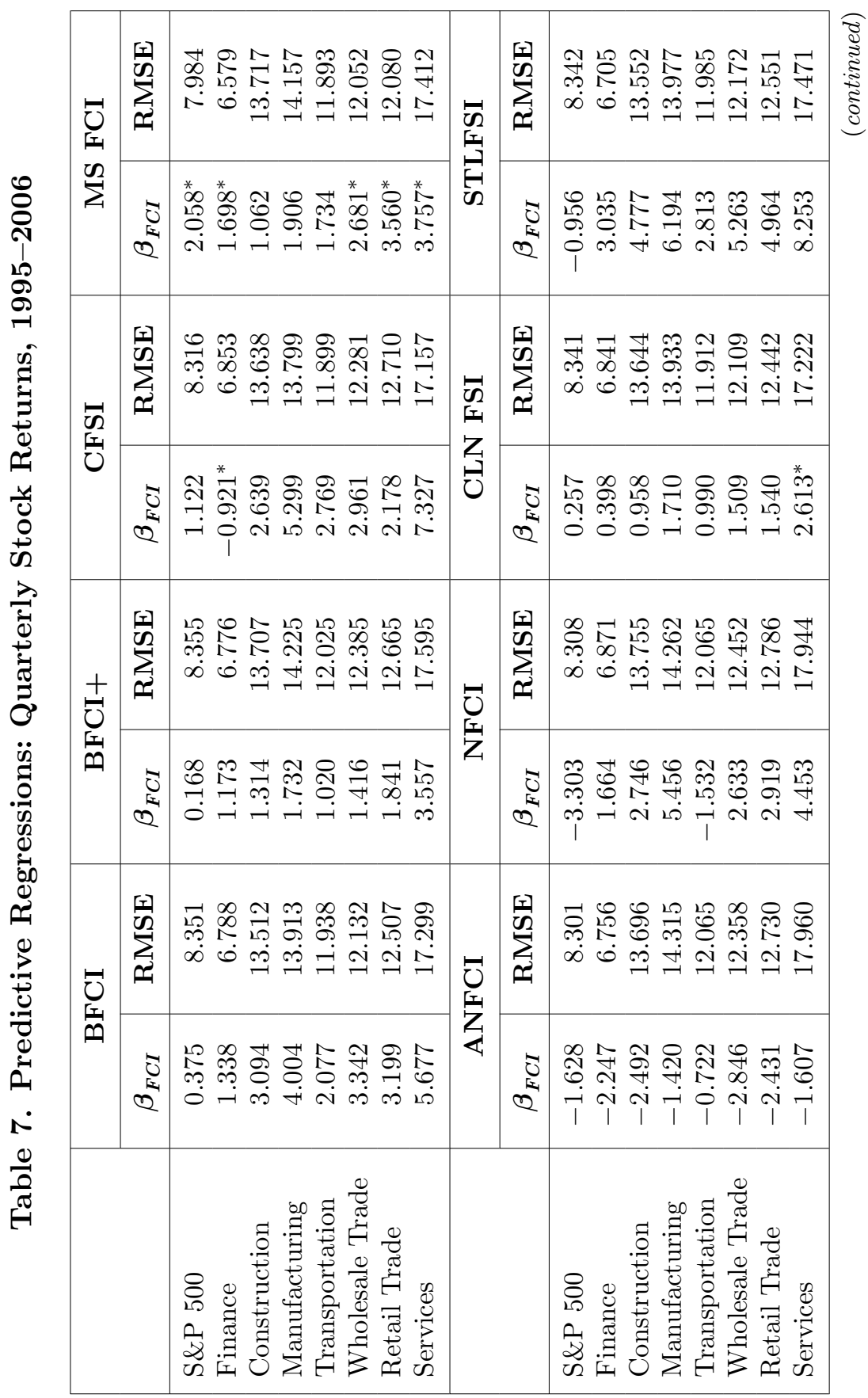




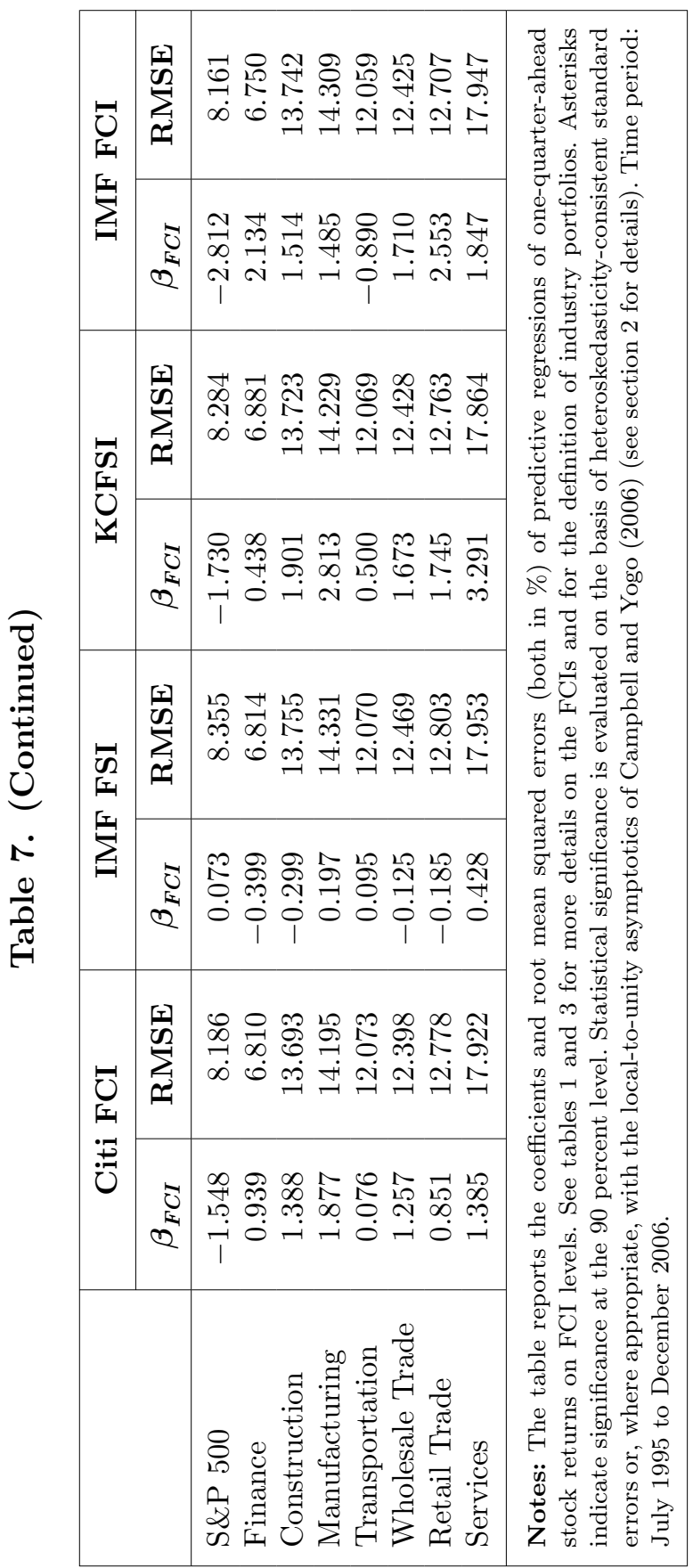


We now discuss whether the FCIs are informative about future innovations to the macroeconomic variables we mentioned earlier in this section. In order to implement the Campbell and Yogo (2006) procedure, the only covariate we include in the predictive regressions is one of the FCIs, and we account for autocorrelation in macroeconomic variable changes by using the residuals from log-change autoregressions as the dependent variable, where the number of lags is chosen on the basis of the Schwarz Bayesian information criterion 7

The first set of results (table 8) focuses on one-month-ahead predictability, with the sample running from 1995 to 20128 The Chicago Fed, St. Louis Fed, Kansas City Fed, and International Monetary Fund (IMF) FCI indexes predict all the variables; most other indexes predict at least three of the six variables. When the sample excludes the 2008 financial crisis (table 9), however, the evidence in favor of predictability is weak, with most indexes being able to predict only one macroeconomic variable, typically industrial production. Similar conclusions can be drawn when focusing on quarterly horizons, as shown in tables 10 and 11 (only the Morgan Stanley index can predict more variables in the short sample than in the full sample) 9

\footnotetext{
${ }^{7}$ For the monthly series, we use two lags for total consumer credit, commercial and industrial loans, industrial production, and total manufacturing inventory, and one lag for durable goods orders and housing starts. For the quarterly series, we use two lags for total consumer credit and total manufacturing inventory, one lag for commercial and industrial loans and industrial production, and zero lags for durable goods orders and housing starts.

${ }^{8}$ While we expect a negative relation between a worsening of current financial conditions and future economic activity, some coefficients in tables 8 and 9 are positive. The reason is that the Campbell and Yogo (2006) procedure requires a negative correlation between current innovations to the dependent variable and the predictor, hence we sometimes need to multiply the FCI by -1 . We systematically check that the sign of the estimated coefficient is as expected: positive if the FCI (multiplied by -1 as applicable) signals stress when low, and negative otherwise.

${ }^{9}$ In an unreported analysis, we obtain similar results when, instead of excluding the period around the financial crisis, we orthogonalize the innovations relative to the appropriately lagged Chicago Fed National Activity Index, which is a proxy for the current state of the economy. The similarity of the results when (i) excluding the crisis and (ii) controlling for the state of the economy is not surprising, especially in a relatively short sample like ours, because the financial crisis also coincided with a severe recession, which exerts a strong leverage effect.
} 


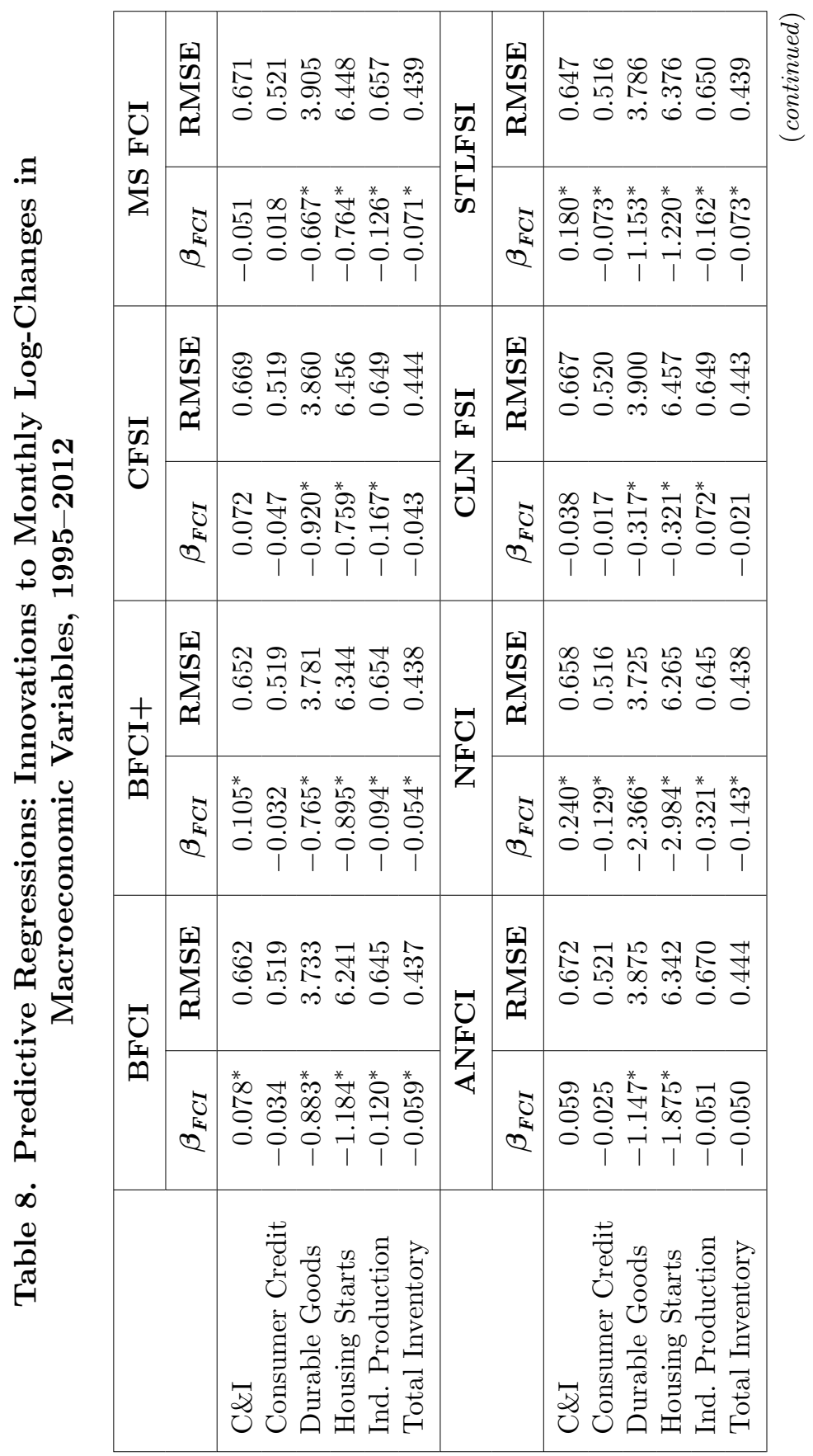




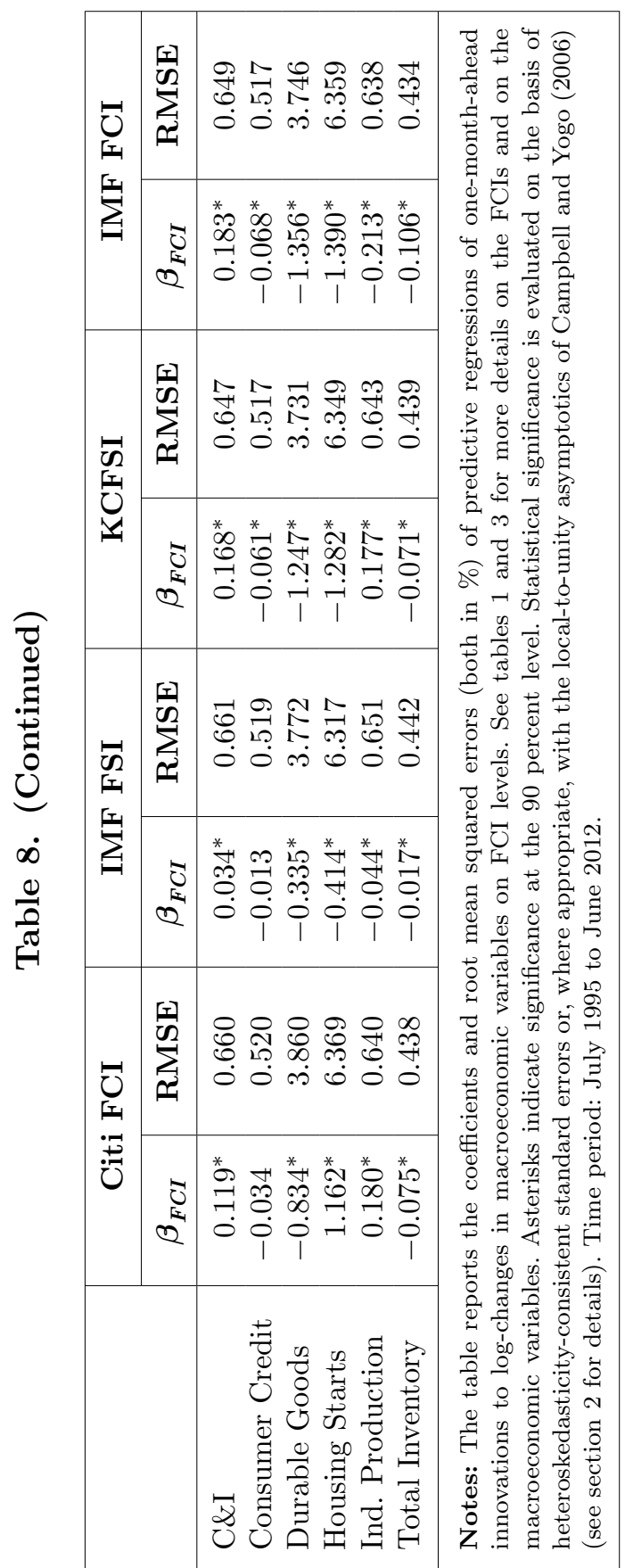




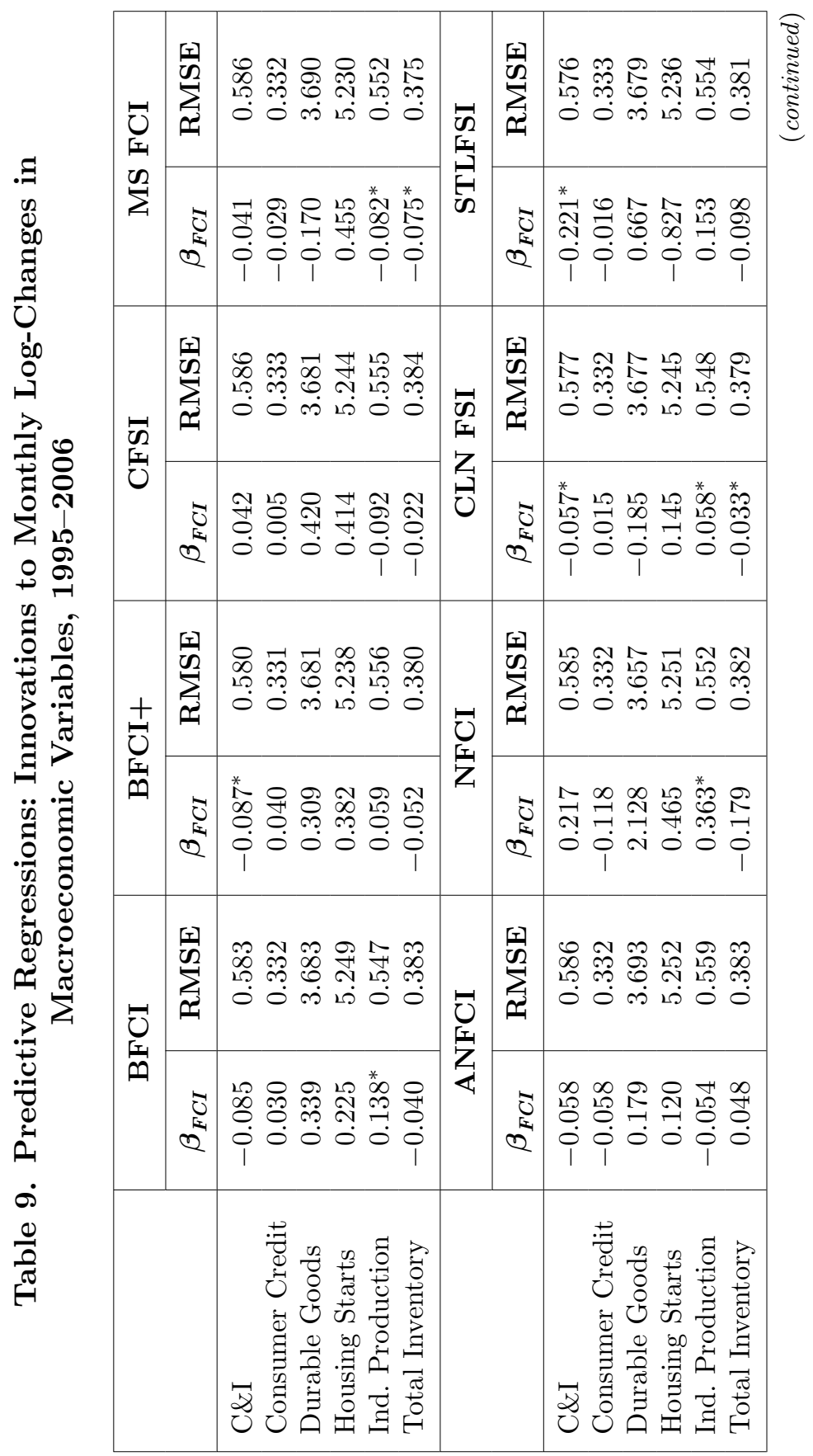




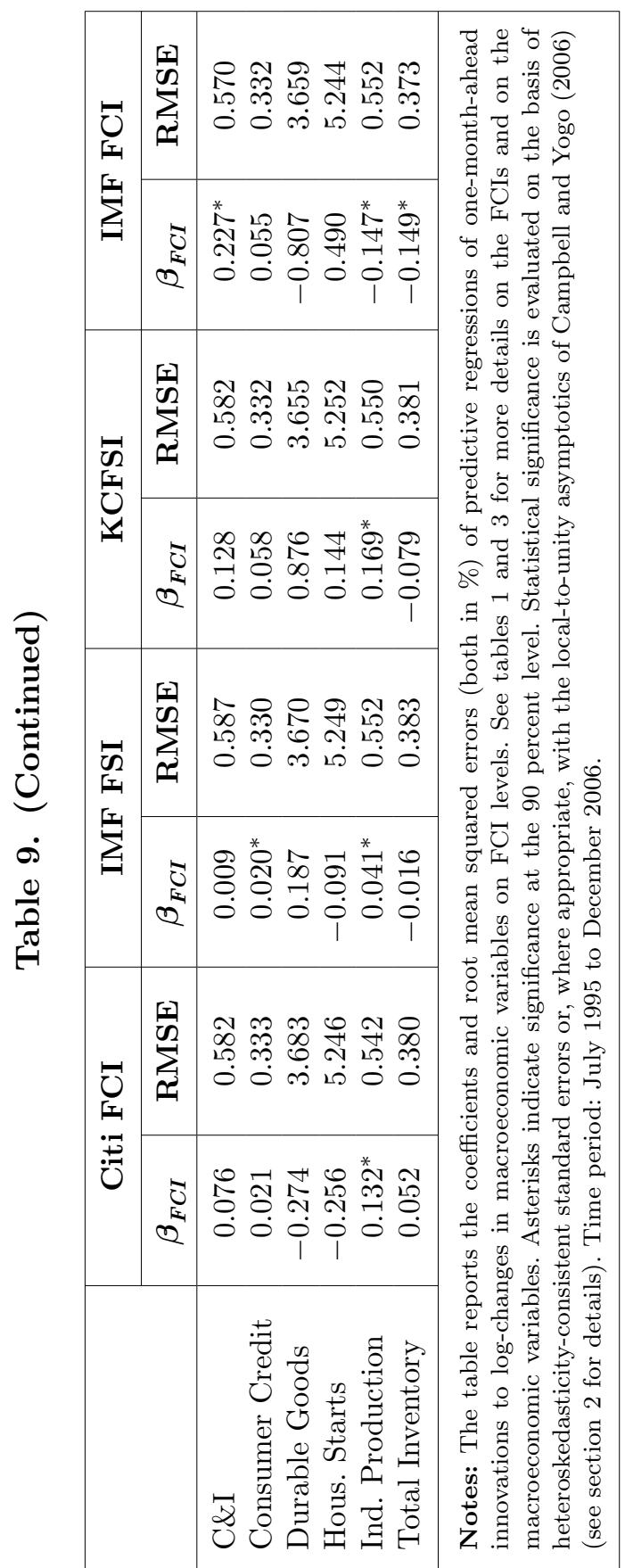




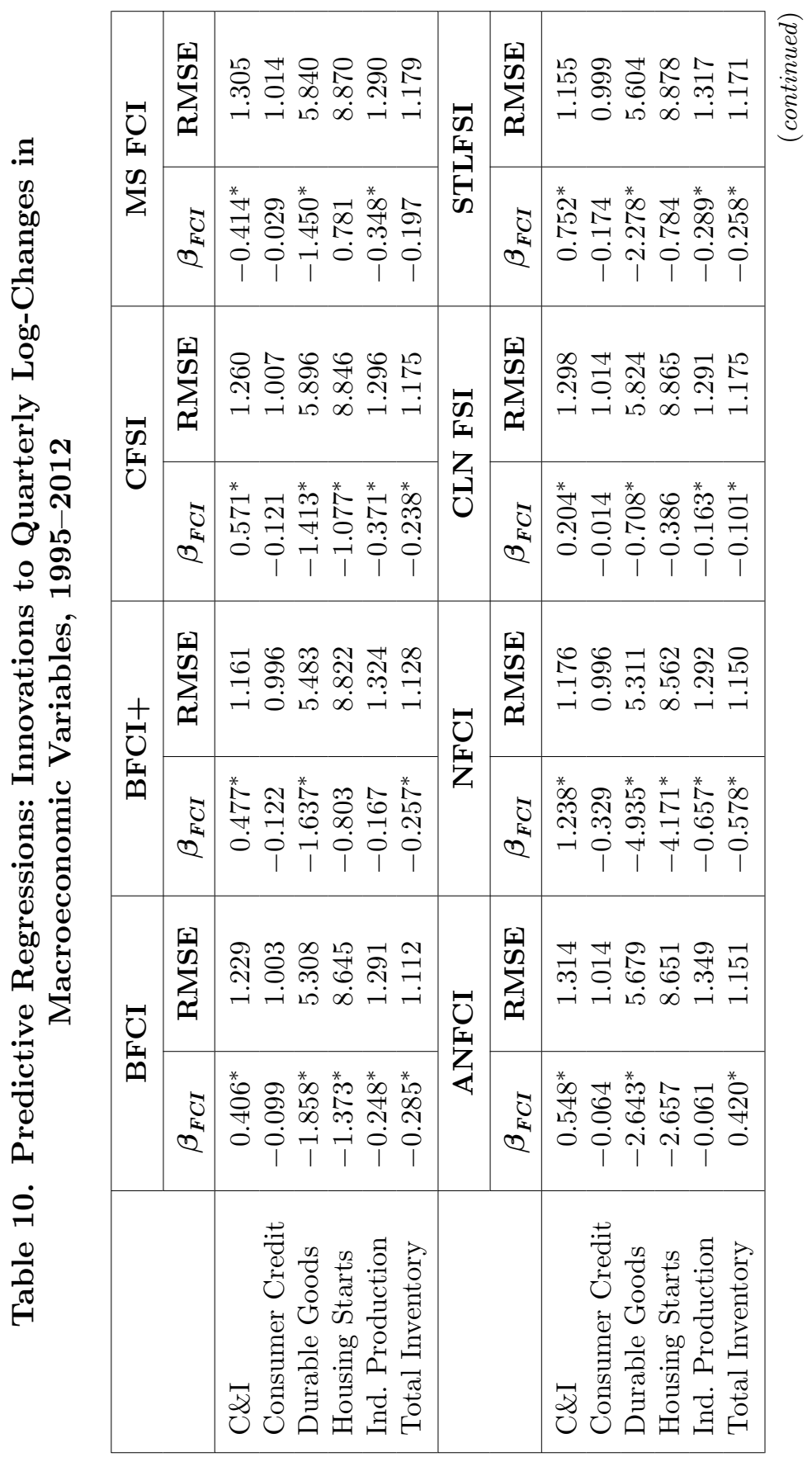




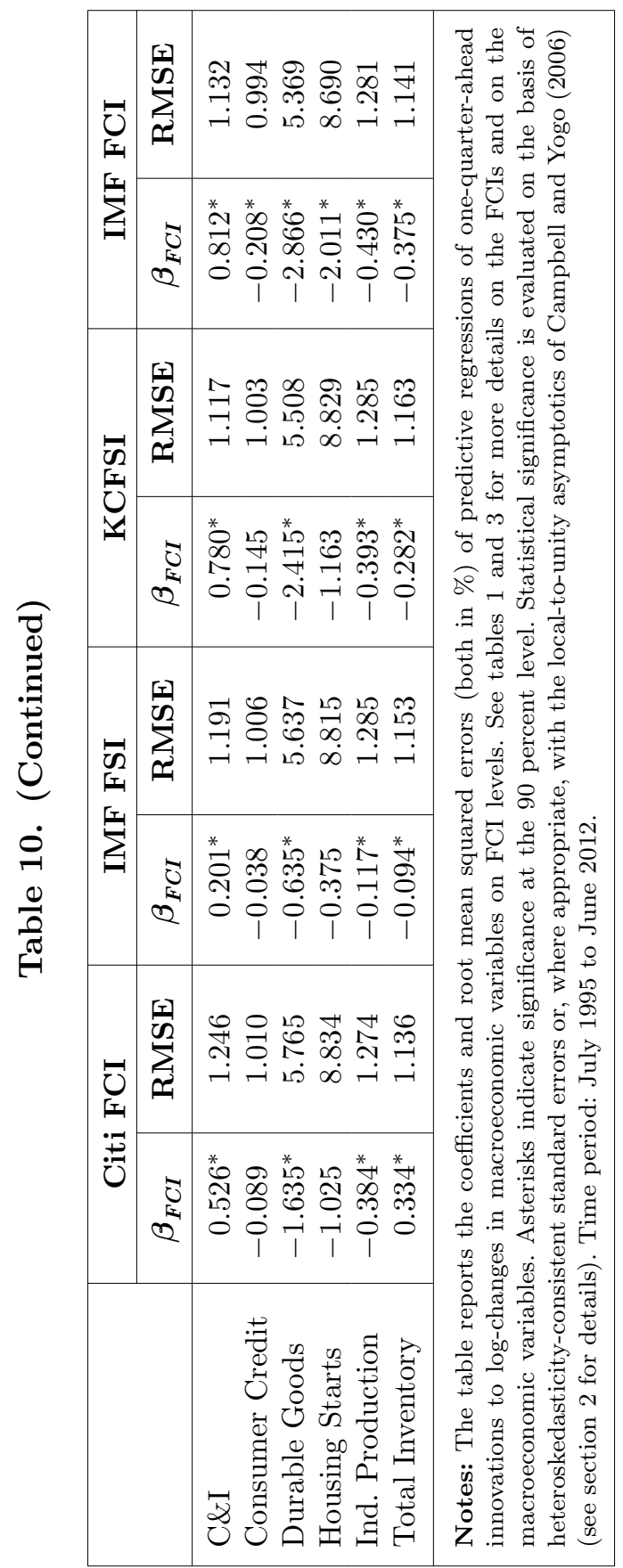




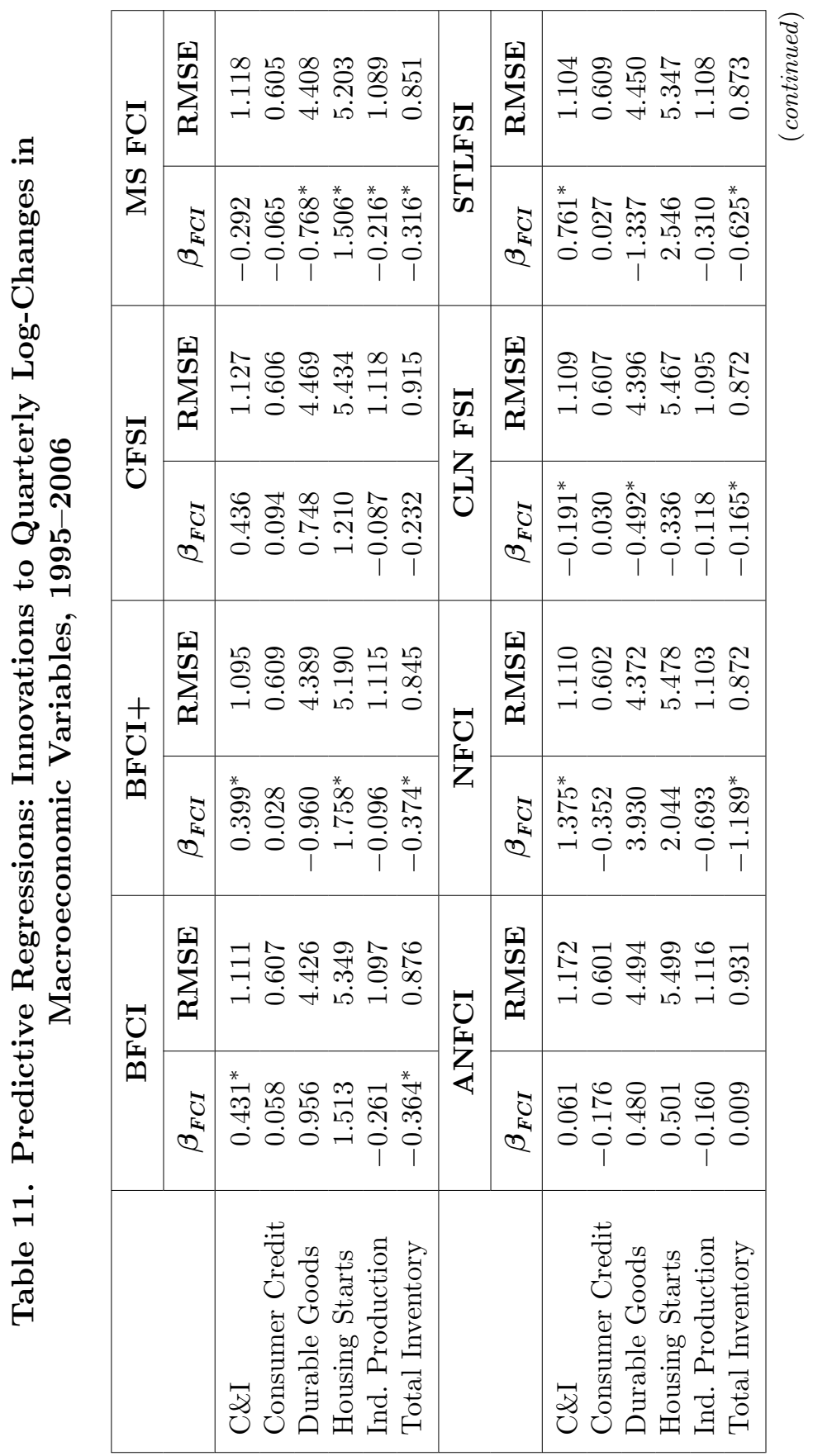




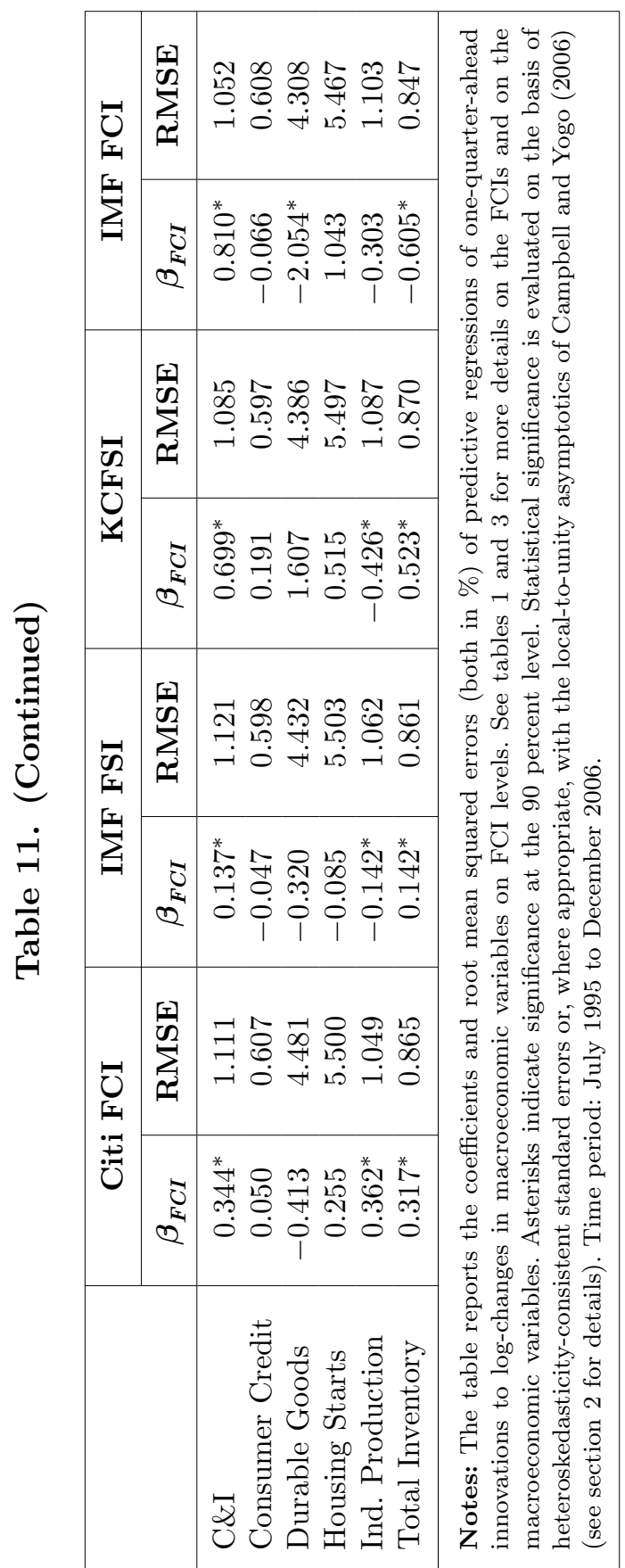




\subsection{Granger Causality Tests}

In the final part of our predictability analysis, we study the relation between each of the FCIs and selected measures of credit availability. Borio (2014) highlights that the financial cycle can amplify macroeconomic fluctuations and contribute to significant economic dislocations, and that one key component of the financial cycle is credit availability. Borio (2014) also suggests that peaks in the financial cycle are closely associated with financial crises, which implies that the results of our tests in this section can provide additional evidence on whether FCIs are a useful signal for an upcoming financial crisis. The measures of credit availability that we consider are consumer credit, mortgage credit, and the issuance of commercial mortgagebacked securities (CMBS), all expressed as a fraction of nominal gross domestic product. The last two variables are directly related to the real estate boom that set the stage for the 2008 financial crisis, with one of them also measuring the importance of credit provision through the securitization channel 10

We depart from the methodology of Campbell and Yogo (2006) when studying the relation between the FCIs and the measures of credit availability, and we conduct a series of Granger causality tests instead. The reason is that it is the overall level of credit availability, rather than its changes or innovations, that contributes to the buildup of financial vulnerabilities during financial booms and that sets the stage for future financial crises (see the discussion in Borio 2014). By using Granger causality tests based on quarterly vector autoregressions with an appropriate number of lags, we can focus on levels and still account for the persistence of both the FCIs and the credit availability variables. We use the procedure described in Toda and Yamamoto (1995) to account for the fact that the FCIs and the credit availability variables may not only be persistent but also potentially integrated in small samples.

\footnotetext{
${ }^{10}$ The consumer credit and mortgage credit data is from the Federal Reserve's Z.1 release. Consumer credit is series LA153166000.Q (household and non-profit organizations; consumer credit), while mortgage credit is series LA153165105.Q (household and non-profit organizations; home mortgages). CMBS issuance is total issuance less Fannie Mae/Freddie Mac, resecuritized, and foreign property issuance, and it is provided by Commercial Mortgage Alert. Nominal gross domestic product is the series GDP from the FRED database of the Federal Reserve Bank of St. Louis.
} 
For each FCI/credit variable pair, we select the optimal number of vector autoregression lags $(m)$ with the Schwarz Bayesian information criterion. We then use augmented Dickey-Fuller tests to determine each series' order of integration, and define $n$ as the maximum order of integration for the two series. Next, we estimate a vector autoregression with $m+n$ lags. Using heteroskedasticityconsistent standard errors, we construct Wald test statistics to determine the joint statistical significance of the coefficients on the first $m$ lags of the FCI in the equation for the credit availability variable, and the joint statistical significance of the coefficients on the first $m$ lags of the credit availability variable in the equation for the FCI. These are the Granger causality tests, and the null hypothesis is that the coefficients are jointly zero. Table 12 reports the resulting p-values.

The top panel of table 12 shows the p-values of tests of whether the FCIs Granger-cause the indicated credit availability measure, and the bottom panel shows the results of tests that the credit availability measures Granger-cause the FCIs. In the left panels we use the full sample, which runs from 1995 to 2012. In the right panels we evaluate to what extent the results are affected by observations corresponding to the financial crisis by setting the 2008 observations of the dependent variables to missing 11 We assess the robustness of the results to the financial crisis by excluding only one year (2008), because the credit availability variables have a strong trend before the crisis and only after 2007 do they exhibit significant variation (Borio 2014 highlights that the financial cycle evolves more slowly than the economic cycle). Truncating the sample after 2007 would have eliminated the variation that is likely most important for identifying the effect we are interested in.

In the full sample, consumer credit, mortgage credit, and CMBS issuance are Granger-caused by five, four, and three FCIs, respectively. After setting the 2008 observations of the credit availability measures to missing, no FCIs Granger-cause CMBS issuance, and three out of twelve still Granger-cause consumer credit and mortgage credit. Focusing on whether the FCIs are Granger-caused by credit availability, only six tests of the seventy-two that we report

\footnotetext{
${ }^{11}$ We set the observations to missing rather than dropping them to avoid using 2007:Q4 as the first lag for 2009:Q1.
} 


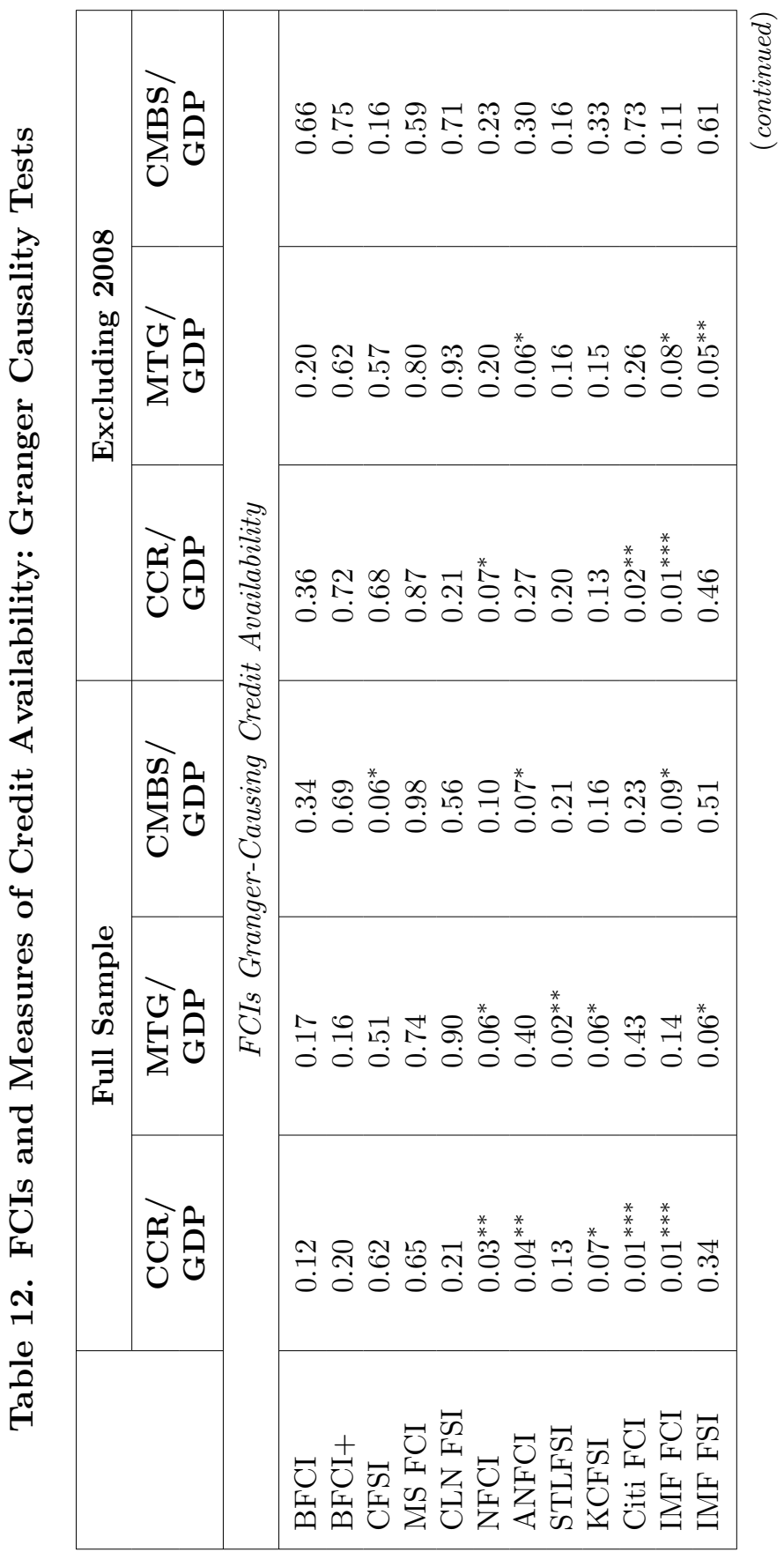




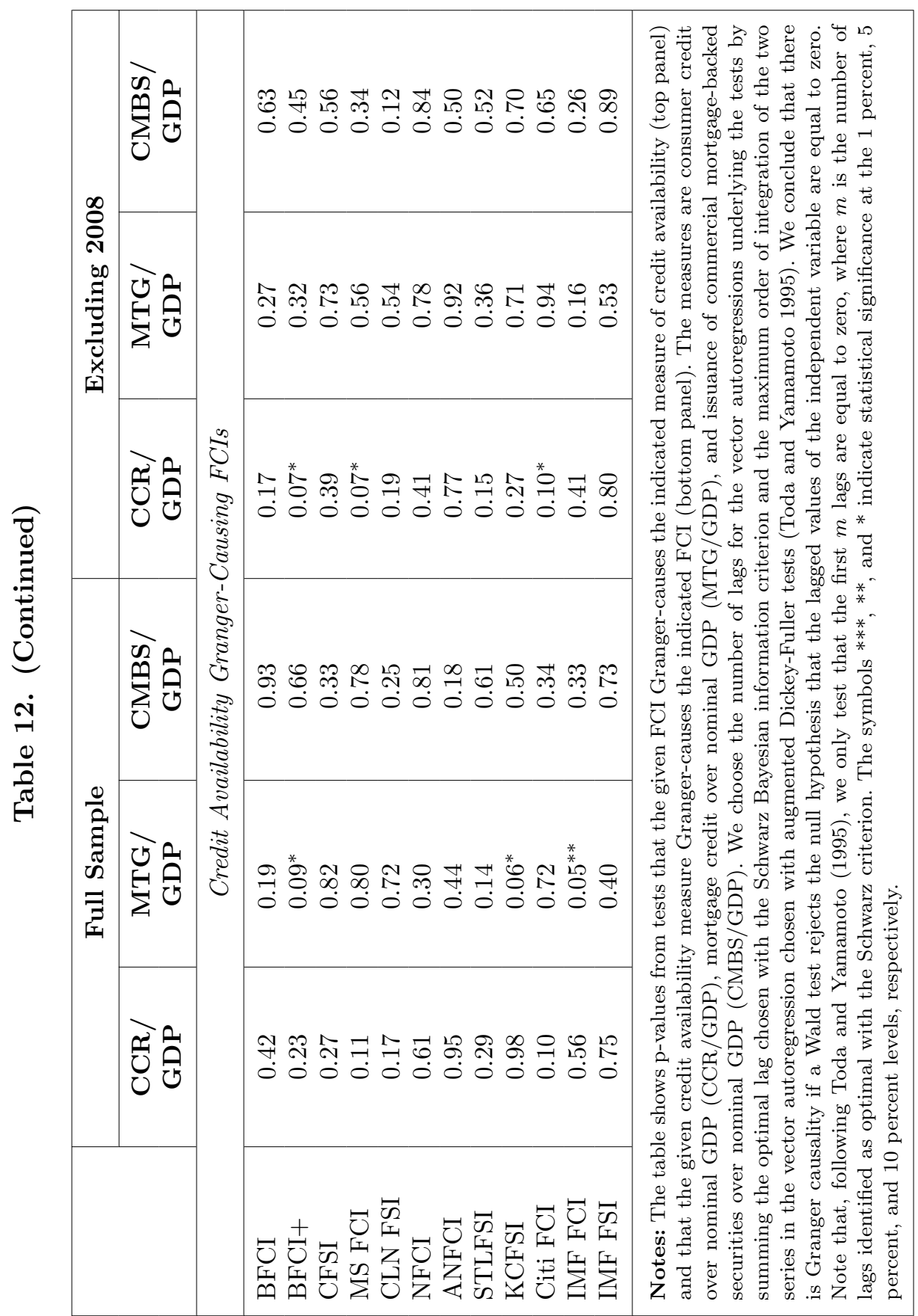


in the bottom panel reject the null of no Granger causality. These results suggest that, if we exclude 2008, neither the FCIs nor the credit availability measures Granger-cause each other. The reason is that only six tests out of thirty-six (16.7 percent) reject the null that the FCIs do not Granger-cause the credit variables, and the number drops to three out of thirty-six ( 8.3 percent) when we test whether the credit variables Granger cause the FCIs. In both cases, the incidence of rejections is roughly in line with the expected number of false positives for tests that have a significance level of 10 percent. In the full sample, the evidence is less clear on whether the FCIs Granger-cause the credit variables, because twelve tests out of thirty-six (33.3 percent) reject the null of no Granger causality. The number of tests that reject the null that the credit variables do not Granger-cause the FCIs remains three out of thirty-six.

\subsection{Interpreting Our Results}

Overall, our opinion is that the empirical evidence in favor of the FCIs having reliable predictive power is weak. Given that the FCIs are built by combining public data for typically highly liquid financial instruments, they can hardly be characterized as containing privileged information. We discuss three possible explanations for the predictability we find in some of our results: threshold effects, data mining, and non-synchronous trading. We ultimately conclude that those results are mainly driven by data mining and by nonsynchronous trading.

The predictability could be the result of threshold effects, in that financial conditions matter only after they deteriorate sufficiently 12 In figure 2 we show a scatter plot of innovations to log-changes of total inventories against the St. Louis FCI, where observations for which the index is above its 80th percentile are highlighted by different shapes. Triangles indicate an observation from between

\footnotetext{
${ }^{12}$ In Kashyap, Lamont, and Stein (1994), for instance, financing constraints at the firm level only become binding in tight-money environments. Hubrich and Tetlow (2012) find that macroeconomic dynamics crucially depend on financial stress, with stress being "of negligible importance in 'normal' times, but of critical importance when the economy is in a high-stress ... state" (page 30).
} 


\section{Figure 2. Threshold Effects}

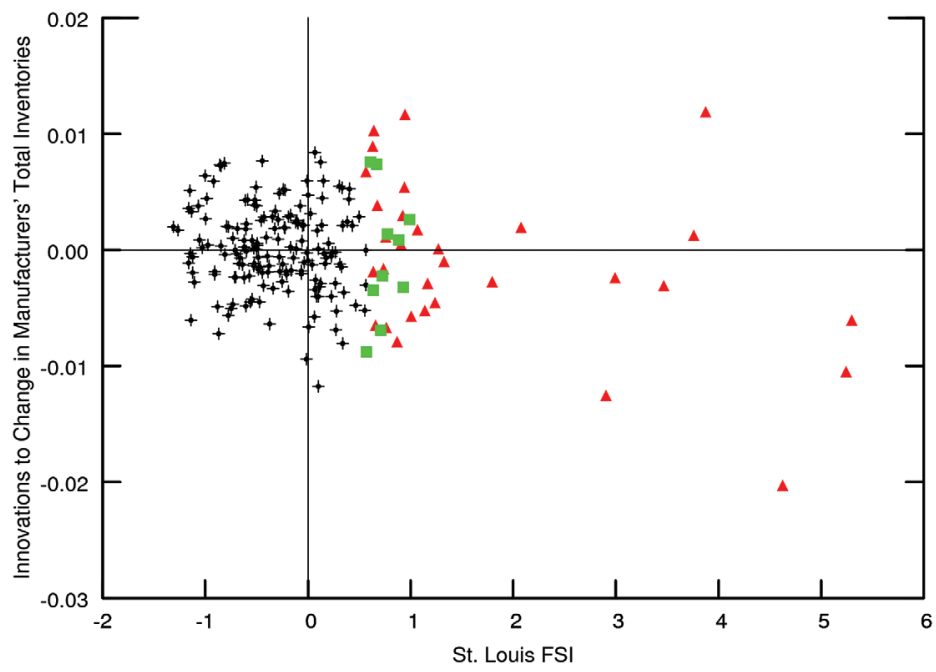

Notes: The plot shows a scatter of innovations to log-changes in total inventories against the Federal Reserve Bank of St. Louis's Financial Stress Index. The squares and triangles correspond to observations for which the index is above its 80th percentile, with the triangles indicating an observation from between 2007 and 2012 and the squares indicating an observation from outside that range. Time period: July 1995 to June 2012.

2007 and 2012, and squares indicate an observation from outside that range 13

The evidence in figure 2 does not clearly point to a threshold effect. There is indeed a negative relationship between the FCI and log-changes in inventories; however, this negative relationship is strong only in the observations from the recent crisis. One possible explanation is that the variables underlying the many FCIs constructed after the 2008 crisis were chosen based on their movements during the crisis. For instance, the FCIs typically include variables like the spread between three-month LIBOR and the three-month Treasury-bill rate (the TED spread), which had unusually large movements during the 2008 crisis. Figure 3 shows the time series of

\footnotetext{
${ }^{13}$ Figure 2 is representative of other index/variable combinations. The unreported figures are available upon request from the authors.
} 


\section{Figure 3. Time Series of the TED Spread}

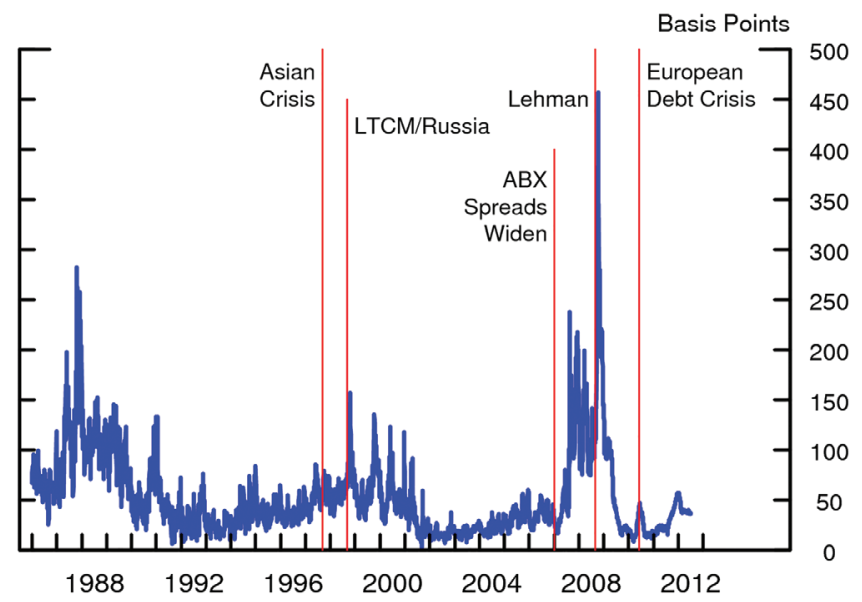

Notes: The graph shows the time series of the spread, in basis points, between the three-month USD LIBOR and the three-month U.S. Treasury yield, which is commonly referred to as the "TED spread." Data are from the British Bankers' Association and the Federal Reserve H.15 statistical release. The vertical lines highlight five events that range from the Asian crisis in 1997 to the European debt crisis in 2010 .

the TED spread from 1986 onwards, and it highlights the unusually high level of the TED spread that was a feature of the 2008 financial crisis. Unfortunately, in practice it is difficult to distinguish a threshold effect from possible data mining, not least because only one major financial crisis is included in the sample.

Another potential source of predictability is non-synchronous trading across markets. Many FCIs, for instance, include the implied volatility index VIX, which is derived from the prices of S\&P 500 index options. These options trade for fifteen minutes after trading in the underlying index ends (4:15 p.m. versus 4:00 p.m. eastern standard time 14 with the consequence that VIX on day $t$ contains information that will be reflected in stock prices only on day $t+1-\mathrm{a}$ fact that can generate spurious predictability (see Atchison, Butler, and Simonds 1987 for a discussion of the effects of non-synchronous

\footnotetext{
${ }^{14}$ Details on the trading hours of S\&P 500 index options can be found at http://www.cboe.com/products/indexopts/spx_spec.aspx
} 
trading on the autocorrelation of equity index returns). We explore this possibility by running predictive regressions on returns that exclude the first day of each holding period.

Table 13 shows that now only five of the twelve FCIs have statistically significant predictive power for the finance portfolio, down from eleven in table 4, suggesting that non-synchronous trading does play a role but is not the sole driver of predictability. In unreported results, we find that excluding the first day of each quarter does not change the significance patterns of tables 6 and 7; most likely, the effect of non-synchronous trading is diluted by the larger variation of returns measured over longer horizons.

The notion that FCIs only have weak predictive power is also supported by a series of Granger causality tests. These tests focus on the dynamic relation between the FCIs and a set of measures for the availability of consumer credit, mortgage credit, and CMBS issuance. Two of these variables are closely related to the housing boom that characterized the 2000s, and CMBS issuance also measures the importance of the securitization channel for the provision of commercial real estate credit. Even though both the variables of interest and the statistical approach are different than in the predictive regression analysis, this additional set of results supports our main conclusion that the FCIs do not have predictive power if one excludes the 2008 financial crisis from the sample.

Finally, we should emphasize that we do not conduct an outof-sample analysis, which would be a more stringent test of predictability, because our in-sample analysis already finds a lack of reliable predictive power.

\section{Combining FCIs}

We now turn to the question of how to consolidate the increasingly large number of indexes into a single proxy for financial conditions. The FCIs themselves are already an aggregation of underlying variables, and the procedure we describe below can be seen as a higherlevel consolidation that aggregates across different variable sets and methodologies, with the objective of reducing model uncertainty for policymakers. As discussed in the introduction, the various FCIs follow similar long-run trends, but they can give significantly different readings on financial conditions at a given point in time (e.g., 


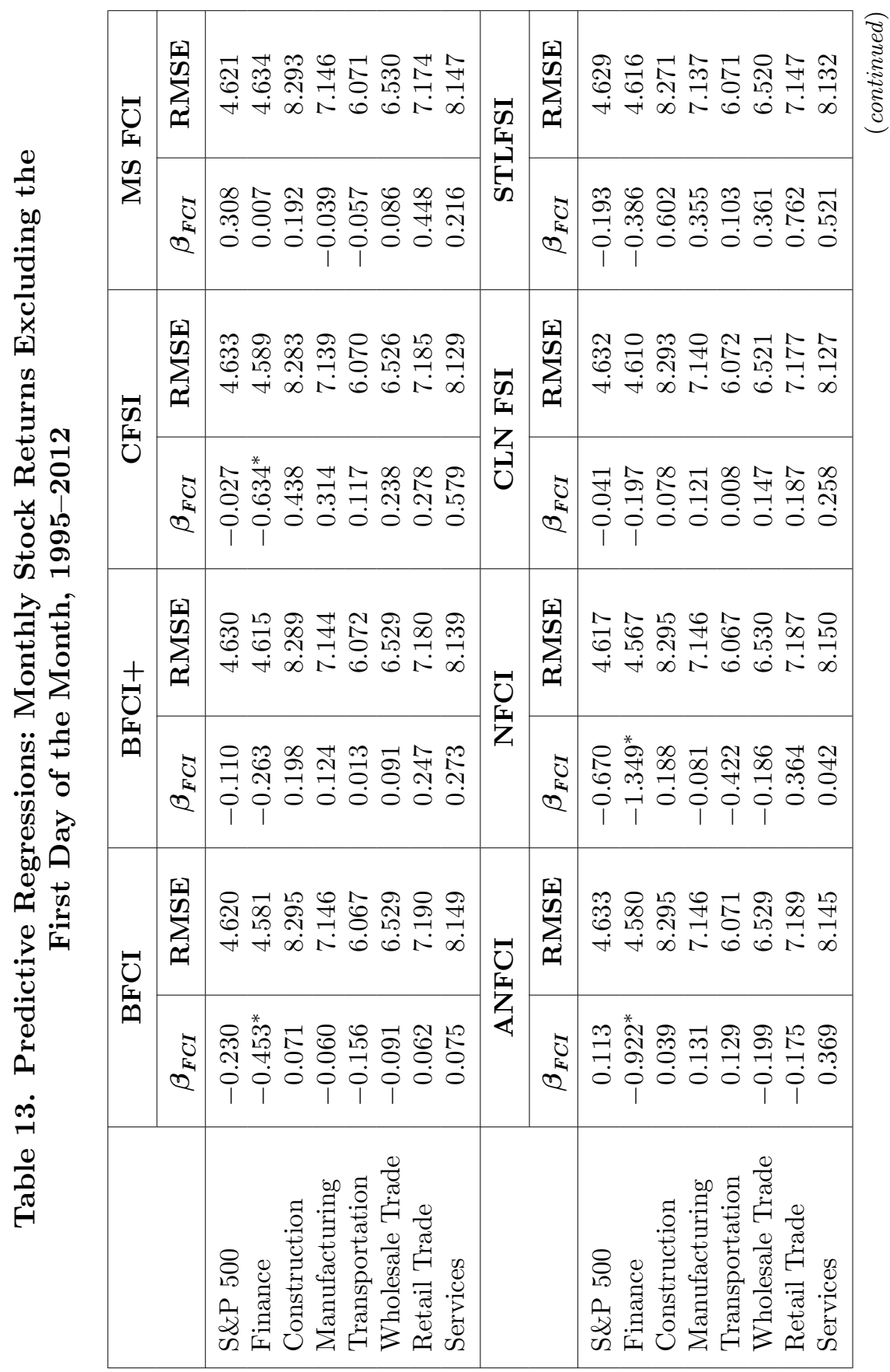




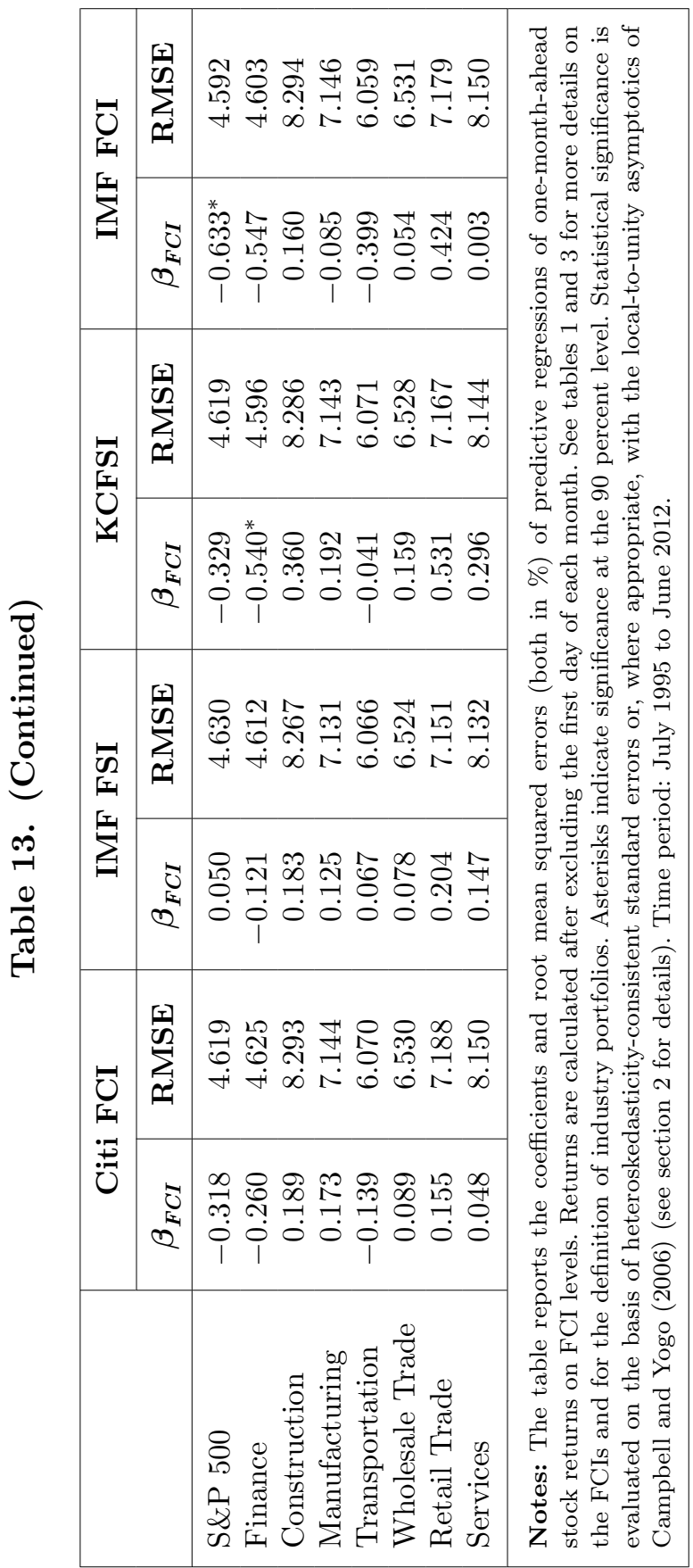


see figure 1). When aggregating the FCIs, we first select a smaller subsample of indexes, and then search for the "best" combination.

In the first step, we sort the individual indexes on the basis of how well they capture the information contained in the remaining FCIs. We measure this ability to capture information using the adjusted $\mathrm{R}^{2}$ from regression 15 of changes in the first principal component of all indexes except for index $i$ on changes in index $i$. Letting $i$ denote the FCI of interest, with $i=1, \ldots, 12$ and "fpc" the first principal component,

$$
\begin{aligned}
P C_{-i} & =\operatorname{fpc}\left(\left\{F C I_{j}\right\}_{j \neq i}\right) \\
\Delta P C_{-i} & =\gamma+\delta \times \Delta F C I_{i}+\varepsilon_{t} .
\end{aligned}
$$

Table 14 reports the adjusted $\mathrm{R}^{2} \mathrm{~s}$ of the regressions described above, which we run on two different samples, 1995-2006 and 1995-2012. The rankings in the two samples are quite similar, with the St. Louis FCI, in particular, having a noticeable margin over the other indexes. We use the ranking to select the five FCIs with the highest adjusted $\mathrm{R}^{2}$ for further aggregation. The two Bloomberg FCIs are ranked among the top five when the sample includes the period surrounding the 2008 financial crisis; however, given that the two indexes are built in a similar way, and that BFCI+ ranks noticeably worse than BFCI in the shorter sample, we exclude BFCI+ from the set of bestperforming indexes. We replace BFCI+ with the Kansas City index, which ranks sixth in the 1995-2012 sample and fifth when excluding the years around the 2008 financial crisis.

Three aspects of our setup warrant further discussion. First, the ranking criterion does not compare the FCIs with a benchmark, because financial conditions are an unobservable factor. We also do not use forecasting errors to select or optimally combine the various predictors (e.g., Timmermann 2006), because in the first part of the paper we find that FCIs are not particularly reliable at forecasting either returns or macroeconomic variables. Second, it is in principle possible that a regression yields a low $\mathrm{R}^{2}$ because index $i$ is a radically better proxy for financial conditions and does not span the remaining FCIs. However, the overlap and the encompassing nature

\footnotetext{
${ }^{15}$ We use robust regressions (Hamilton 1991), which reduce the influence of outliers.
} 


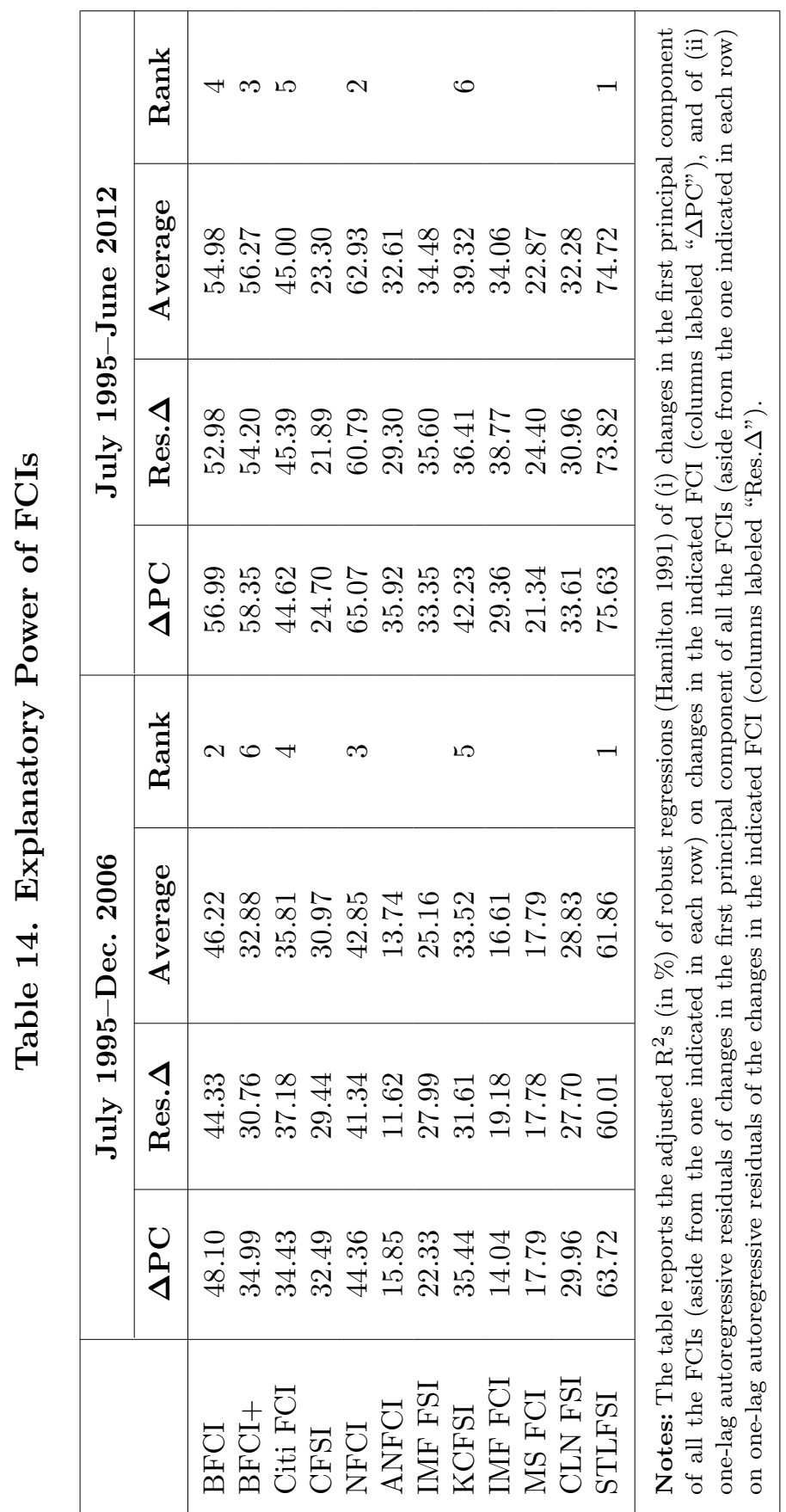


of the variables that underlie the different indexes make such a possibility unlikely. Third, we choose to select five FCIs, and the choice of this number is admittedly arbitrary, but the key point is that we are able to reduce the number of combinations we consider, thus lowering the likelihood that our results are driven by data mining.

In the second step we form all combinations of the five indexes selected above 16 calculate each combination's first principal component, and regres 17 changes in the first principal component of the FCIs that are not in the combination under consideration (out of the twelve we study) on changes in the first principal component of the combination. Letting $C$ denote the combination of interest,

$$
\begin{aligned}
P C_{\notin \mathbf{C}} & =\operatorname{fpc}\left(\left\{F C I_{j}\right\}_{j \notin \mathbf{C}}\right) \\
P C_{\in \mathbf{C}} & =\operatorname{fpc}\left(\left\{F C I_{j}\right\}_{j \in \mathbf{C}}\right) \\
\Delta P C_{\notin \mathbf{C}} & =\gamma+\delta \times \Delta P C_{\in \mathbf{C}}+\varepsilon_{t} .
\end{aligned}
$$

In order to minimize the risk of overfitting, the regressions are run on several subsamples, and we use the resulting set of adjusted $\mathrm{R}^{2}$ to select the "best" combination of FCIs. Specifically, we calculate, for each combination and in each subsample, the squared deviation of the combination's adjusted $\mathrm{R}^{2}$ relative to the highest adjusted $\mathrm{R}^{2}$ in each subsample. We then average, for each combination, the squared deviations across time periods, and use the averages to identify the "best" composite FCI. Table 15 reports five averages: the first (column A) shows arithmetic averages; in the second (B) the average is weighted by the ratio of daily $\mathrm{S} \& \mathrm{P} 500$ return volatility in each subsample over the volatility in the full sample; in the third (C) it is weighted by the ratio of the average VIX level in each subsample over the average VIX level in the full sample; in the fourth (D) weights are based on the volatility of daily VIX changes; in the fifth (E) the arithmetic average is calculated on the four non-overlapping samples (7/95-12/98 through 1/06-6/12).

The criterion we use to rank the FCIs is, of course, one of potentially many. For example, we could have selected the FCIs with the

\footnotetext{
${ }^{16}$ We form thirty-one different combinations: five individual indexes, ten sets of two indexes, ten sets of three indexes, five sets of four indexes, and one set of five indexes.

${ }^{17}$ We again use robust regressions (see Hamilton 1991).
} 


\begin{tabular}{|c|c|c|c|}
\hline 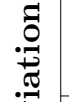 & 뙤 & 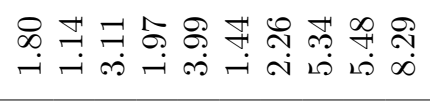 & 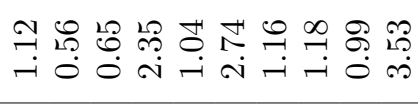 \\
\hline 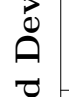 & A & 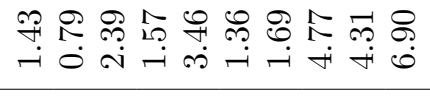 & 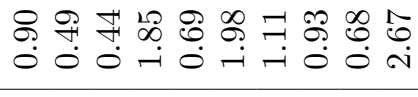 \\
\hline 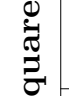 & U & 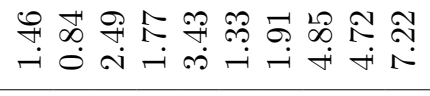 & 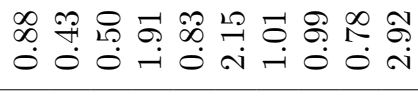 \\
\hline $\begin{array}{l}\boldsymbol{U} \\
0 \\
20 \\
\tilde{\sigma}\end{array}$ & $\oplus$ & 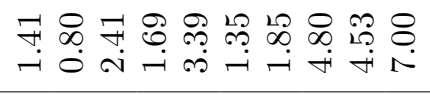 & 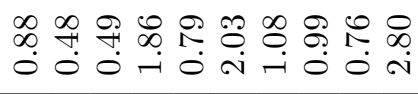 \\
\hline 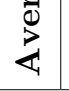 & $<$ & 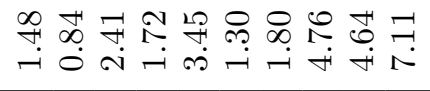 & 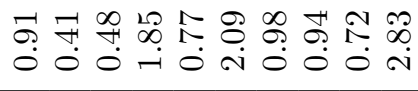 \\
\hline & & 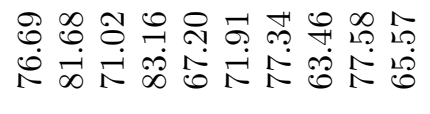 & 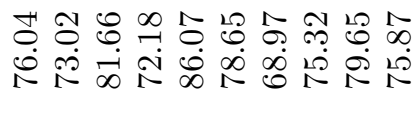 \\
\hline & & 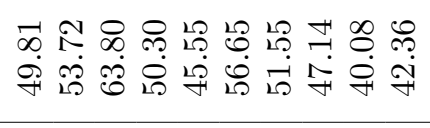 & 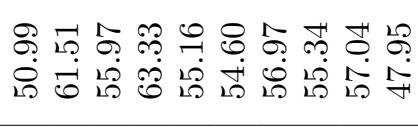 \\
\hline & & 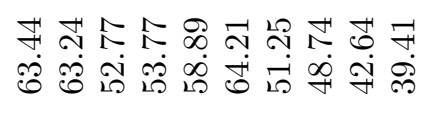 & 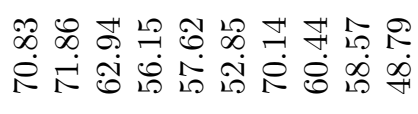 \\
\hline & & 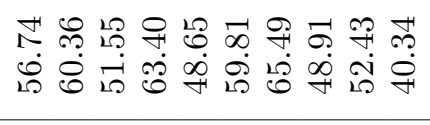 & 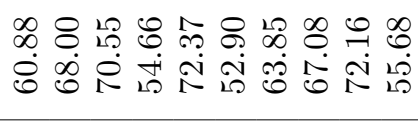 \\
\hline & & 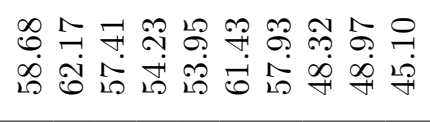 & 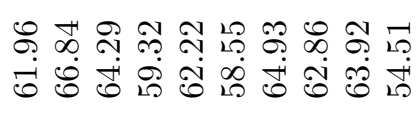 \\
\hline & & 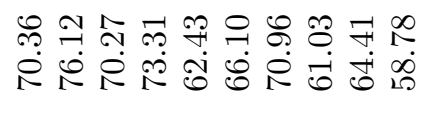 & 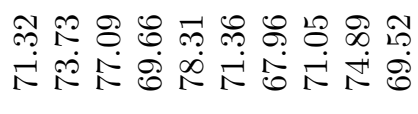 \\
\hline & 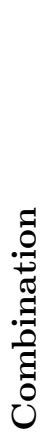 & 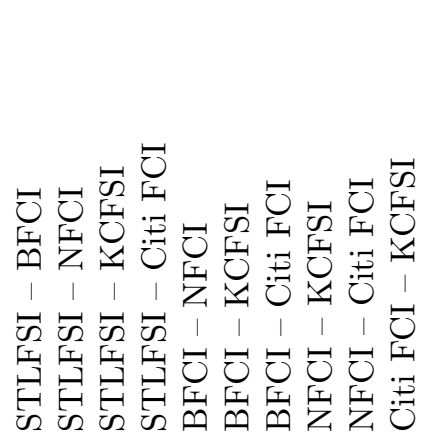 & 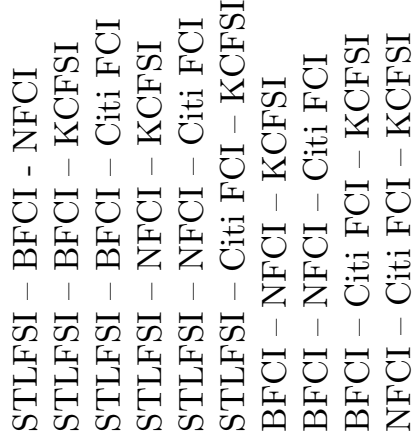 \\
\hline
\end{tabular}




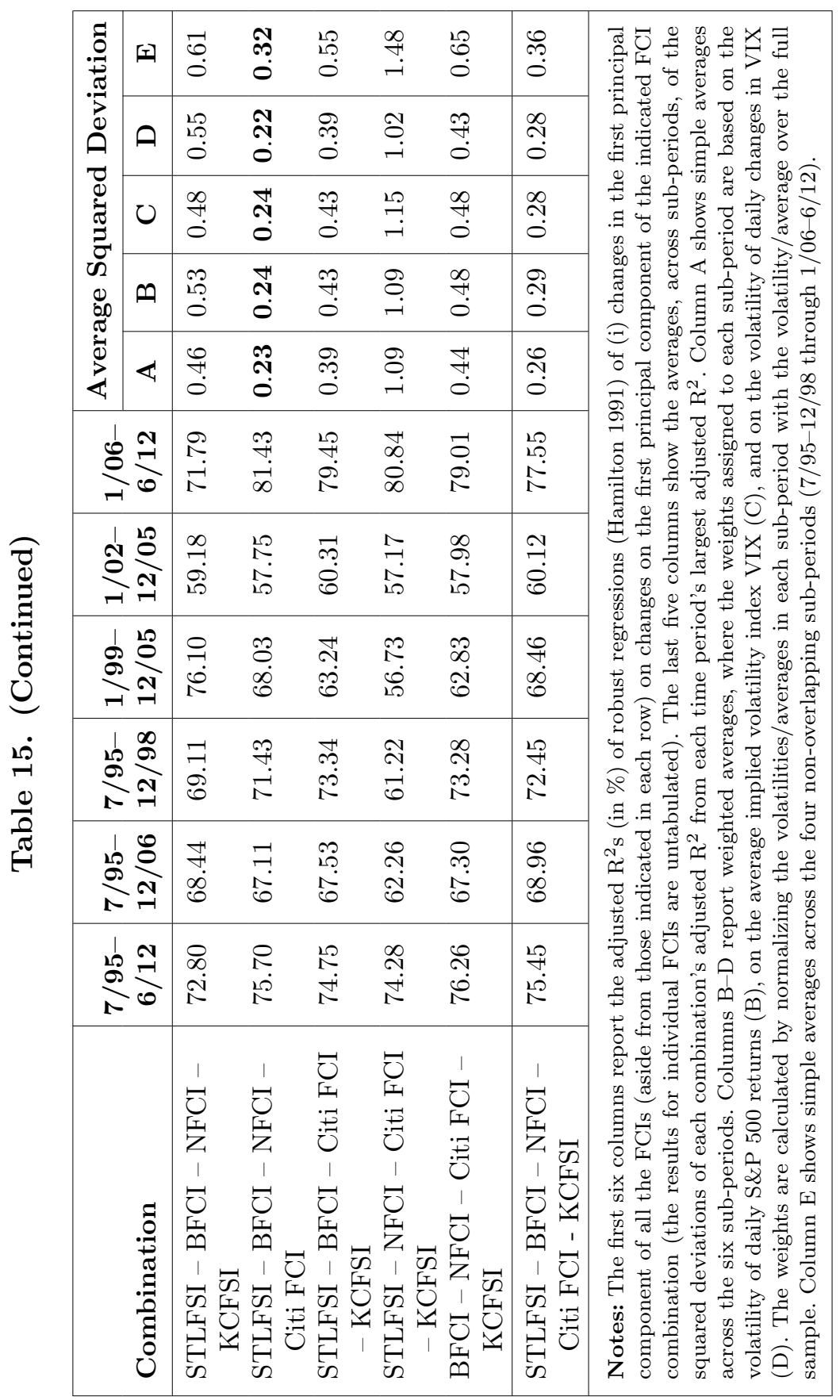


lowest volatility. Such choice would have implied an assumption on the way financial conditions change over time, namely that they evolve smoothly. Choosing the FCIs with the highest volatility would have implied that we assume financial conditions can change rapidly, and that we are looking for a more reactive proxy. Precisely to avoid imposing strong assumptions on the nature of the process for financial conditions, we have adopted a criterion that only assumes that (i) all the indexes we study provide some information about financial conditions, and (ii) none of the indexes is likely to contain uniquely accurate information about financial conditions.

The results in table 15 show (in bold) that the first principal component of the St. Louis Fed, Bloomberg, Chicago Fed, and Citi indexes has the lowest average squared deviations in all columns (A)-(E): hence we consider such combination our composite FCI (CFCI). Figure 4 highlights that the CFCI follows the general pattern of the individual FCIs, but its volatility exhibits different regimes depending on whether financial conditions are loose or tight. The three graphs in figure 4 show the CFCI against three alternative proxies for financial conditions: STLFSI, which is the bestperforming individual FCI; the first principal component of STLFSI and of the index with the lowest correlation with STLFSI (MS FCI); and the implied volatility index VIX, which is one of the variables underlying many FCIs. The CFCI tracks STLFSI closely, although the latter is less volatile in the years following the bull market of the late 1990s. The first principal component of STLFSI and of MS FCI is more volatile than the CFCI, especially in the earlier part of the sample, and it points to much more improved conditions than the CFCI in early 2008, just before the crisis gained full traction.

A comparison of VIX and the CFCI shows that the two track each other quite well, with the exception of the period between mid2007 and late 2008, when VIX remains stable, and the CFCI shows a largely steady deterioration in financial conditions. In addition, the CFCI points to loose financial conditions in the second half of the 1990s until late 1998, while, over the same period, VIX points to slowly deteriorating conditions starting in 1995. In figure 5, we plot the twenty-four-month exponentially weighted rolling correlation between VIX changes and changes in the CFCI, where observations are weighted so that the weight decays by 50 percent every twelve months (see figure 5 for details). The correlation is initially 


\section{Figure 4. The Composite FCI and Other Proxies of Financial Conditions}
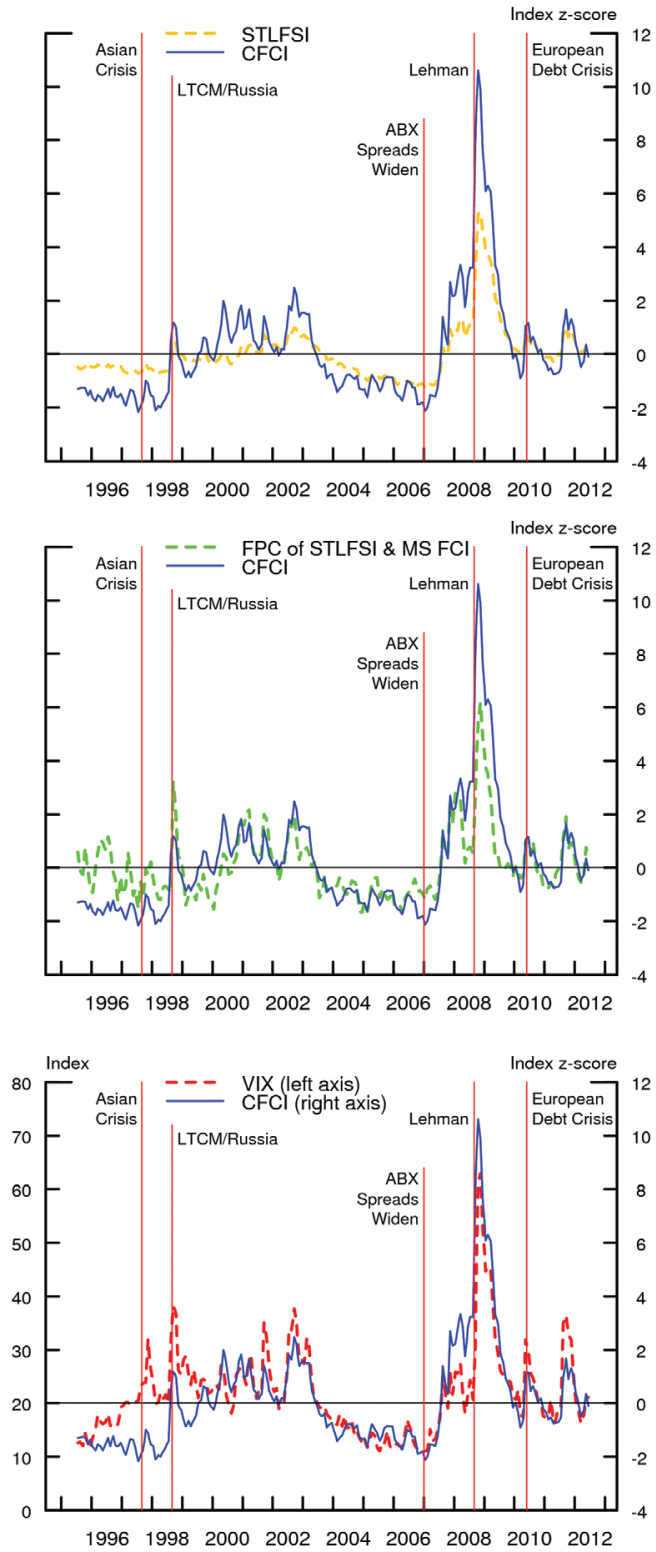

Notes: Each of the three graphs shows the composite FCI (CFCI, solid line) against one of three alternative proxies for financial conditions: the STLFSI (top graph), which is the individual FCI that best summarizes the information in the remaining FCIs (see table 14); the first principal component of the STLFSI and of the index that is least correlated with the STLFSI (the MS FCI-middle graph); and the implied volatility index VIX (bottom graph). VIX data are from the Chicago Board Options Exchange. 


\section{Figure 5. Exponentially Weighted Correlation between VIX Changes and Changes in the Composite FCI}

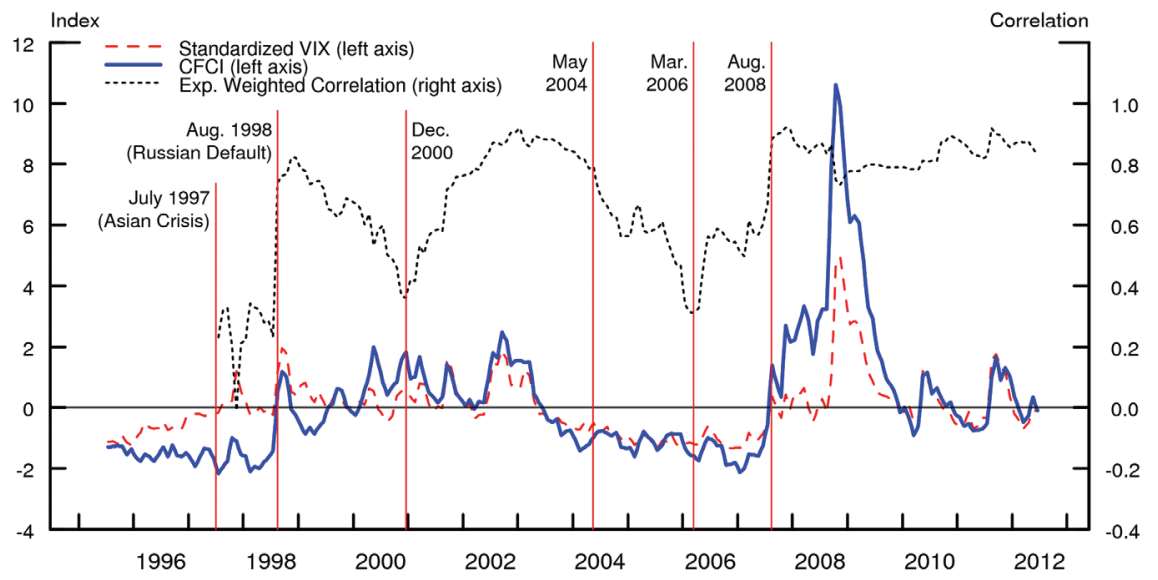

Notes: The graph shows exponentially weighted correlation (dotted line) between monthly changes in the volatility index VIX and monthly changes in the composite FCI, together with the VIX index, which is standardized for scale reasons (dashed line), and the composite FCI (CFCI, solid line). The correlation is calculated on the basis of a twenty-four-month rolling window, where the weights decay by 50 percent every twelve months. Specifically, the weights assigned to observations $\{t-i\}_{i=0}^{23}$ are given by $\frac{1}{0.75} \cdot \alpha \cdot(1-\alpha)^{i}$, where $\alpha=1-e^{\frac{-\ln (4)}{24}}$.

low, but it jumps to about 80 percent with the Russian default in August 1998. With the exception of two relatively short periods in late 2000 and 2005/06, it stays mostly above 50 percent, and it has been around 80-90 percent since the events of the late summer of 2008 .

\section{Conclusion}

We provide an assessment of the one-month-ahead and one-quarterahead predictive power that a selection of financial conditions indexes (FCIs) have for returns on a broad equity index and a set of equity industry portfolios and for innovations to log-changes in macroeconomic variables. Our analysis is based on local-to-unity asymptotics, which allows for accurate statistical inference in the 
presence of persistent predictors. We find that the evidence for predictive power at the horizons we consider is generally weak, unless the financial crisis is included. Further, part of the predictive power is driven by the effects of non-synchronous trading and, potentially, data mining. We also study the relation between the FCIs and consumer credit, mortgage credit, and the issuance of commercial mortgage-backed securities, and find only limited evidence that the FCIs Granger-cause these variables. Based on these results, we conclude that FCIs are better used as aggregate indicators of current financial conditions.

We also observe that, even in the months leading to the 2008 financial crisis, different FCIs can provide conflicting assessments of financial conditions. We suggest a procedure for combining the various FCIs into a single proxy, which can help reduce the uncertainty facing policymakers when monitoring financial conditions. Our procedure builds on the modest assumptions that all the FCIs we study provide some information about financial conditions, yet no index contains uniquely accurate information.

\section{References}

Atchison, M., K. Butler, and R. Simonds. 1987. "Nonsynchronous Security Trading and Market Index Autocorrelation." Journal of Finance 42 (1): 111-18.

Bernanke, B. 1983. "Nonmonetary Effects of the Financial Crisis in the Propagation of the Great Depression." American Economic Review 73 (3): 257-76.

Bernanke, B., and A. Blinder. 1992. "The Federal Funds Rate and the Channels of Monetary Transmission." American Economic Review 82 (4): 901-21.

Bollerslev, T., G. Tauchen, and H. Zhou. 2009. "Expected Stock Returns and Variance Risk Premia." Review of Financial Studies 22 (11): 4463-92.

Borio, C. 2014. "The Financial Cycle and Macroeconomics: What Have We Learnt?" Journal of Banking and Finance 45: 182-98. Brave, S., and R. Butters. 2010. "Gathering Insights on the Forest from the Trees: A New Metric for Financial Conditions." Working Paper No. 2010-07, Federal Reserve Bank of Chicago. 
Calomiris, C., and J. Mason. 2003. "Consequences of Bank Distress During the Great Depression." American Economic Review 93 (3): 937-47.

Campbell, J., and M. Yogo. 2006. "Efficient Tests of Stock Return Predictability." Journal of Financial Economics 81 (1): 27-60.

Campello, M., J. Graham, and C. Harvey. 2010. "The Real Effects of Financial Constraints: Evidences from a Financial Crisis." Journal of Financial Economics 97 (3): 470-87.

Cardarelli, R., S. Elekdag, and S. Lall. 2011. "Financial Stress and Economic Contractions." Journal of Financial Stability 7 (2): 78-97.

Carlson, M., K. Lewis, and W. Nelson. 2014. "Using Policy Intervention to Identify Financial Stress." International Journal of Finance and Economics 19 (1): 59-72.

Chava, S., and A. Purnanandam. 2011. "The Effect of Banking Crisis on Bank-Dependent Borrowers." Journal of Financial Economics 99 (1): 116-35.

D'Antonio, P. 2008. "Appendix." In EMA Special Report, 26-28. Citigroup Global Markets Inc.

English, W., K. Tsatsaronis, and E. Zoli. 2005. "Assessing the Predictive Power of Measures of Financial Conditions for Macroeconomic Variables." BIS Papers 22 (April): 228-52.

Gertler, M., and S. Gilchrist. 1994. "Monetary Policy, Business Cycles, and the Behavior of Small Manufacturing Firms." Quarterly Journal of Economics 109 (2): 309-40.

Hakkio, C., and W. Keeton. 2009. "Financial Stress: What Is It, How Can It Be Measured, and Why Does It Matter?" Economic Review (Federal Reserve Bank of Kansas City) (Q2): 5-50.

Hamilton, L. 1991. "srd1: How Robust Is Robust Regression?" Stata Technical Bulletin 2: 21-26.

Hatzius, J., P. Hooper, F. Mishkin, K. Schoenholtz, and M. Watson. 2010. "Financial Conditions Indexes: A Fresh Look After the Financial Crisis." NBER Working Paper No. 16150.

Hubrich, K., and R. Tetlow. 2012. "Financial Stress and Economic Dynamics: The Transmission of Crises." FEDS Paper No. 201282, Board of Governors of the Federal Reserve System. 
Kashyap, A., O. Lamont, and J. Stein. 1994. "Credit Conditions and the Cyclical Behavior of Inventories." Quarterly Journal of Economics 109 (3): 565-92.

Kashyap, A., and J. Stein. 2000. "What Do a Million Observations on Banks Say about the Transmission of Monetary Policy?" American Economic Review 90 (3): 407-28.

Kashyap, A., J. Stein, and D. Wilcox. 1993. "Monetary Policy and Credit Conditions: Evidence from the Composition of External Finance." American Economic Review 83 (1): 78-98.

Khwaja, A., and A. Mian. 2008. "Tracing the Impact of Bank Liquidity Shocks: Evidence from an Emerging Market." American Economic Review 98 (4): 1413-42.

Kliesen, K., M. Owyang, and E. Vermann. 2012. "Disentangling Diverse Measures: A Survey of Financial Stress Indexes." Review (Federal Reserve Bank of St. Louis) 94 (5): 369-97.

Kliesen, K., and D. Smith. 2010. "Measuring Financial Market Stress." Economic Synopses (Federal Reserve Bank of St. Louis) (2).

Ludvigson, S., and S. Ng. 2007. "The Empirical Risk-Return Relation: A Factor Analysis Approach." Journal of Financial Economics 83 (1): 171-222.

Matheson, T. 2012. "Financial Conditions Indexes for the United States and Euro Area." Economics Letters 115 (3): 441-46.

Oet, M., R. Eiben, T. Bianco, D. Gramlich, and S. Ong. 2011. "The Financial Stress Index: Identification of Systemic Risk Conditions." Working Paper No. 11-30, Federal Reserve Bank of Cleveland.

Paravisini, D. 2008. "Local Bank Financial Constraints and Firm Access to External Finance." Journal of Finance 63 (5): 2161-93.

Peek, J., and E. Rosengren. 1997. "The International Transmission of Financial Shocks: The Case of Japan." American Economic Review 87 (4): 495-505.

_ 2000. "Collateral Damage: Effects of the Japanese Bank Crisis on Real Activity in the United States." American Economic Review 90 (1): 30-45.

Rosenberg, M. R. 2009. "Global Financial Market Trends and Policy." Bloomberg Financial Conditions Watch 2 (6). 
Stock, J., and M. Watson. 2002. "Macroeconomic Forecasting Using Diffusion Indexes." Journal of Business and Economic Statistics 20 (2): $147-62$.

Timmermann, A. 2006. "Forecast Combinations." In Handbook of Economic Forecasting, Vol. 1, ed. G. Elliott, C. W. J. Granger, and A. Timmermann, 135-96 (chapter 4). North-Holland.

Toda, H., and T. Yamamoto. 1995. "Statistical Inference in Vector Autoregressions." 